\title{
Impact of Ionic Liquid 1-Ethyl-3-Methylimidazolium Acetate Mediated Extraction on Lignin Features
}

\author{
Idi Guga Audu ${ }^{1,2,3,4}$, Isabelle Ziegler-Devin'2, Heiko Winter ${ }^{1,3}$, Martina Bremer ${ }^{4}$, Anton Hoffmann ${ }^{4}$, \\ Steffen Fischer, Marie-Pierre Laborie ${ }^{1,3}$, Nicolas Brosse ${ }^{2 *}$ \\ ${ }^{1}$ Chair of Forest Biomaterials, University of Freiburg, Freiburg, Germany \\ ${ }^{2}$ LERMaB, Faculty of Science and Technology, University of Lorraine, Nancy, France \\ ${ }^{3}$ Freiburg Materials Research Center (FMF), Freiburg, Germany \\ ${ }^{4}$ Institute of Plant and Wood Chemistry, Technische Universität Dresden, Dresden, Germany \\ Email: ^Nicolas.Brosse@univ-lorraine.fr
}

How to cite this paper: Audu, I.G., Ziegler-Devin, I., Winter, H., Bremer, M., Hoffmann, A., Fischer, S., Laborie, M.-P. and Brosse, N. (2017) Impact of Ionic Liquid 1-Ethyl-3-Methylimidazolium Acetate Mediated Extraction on Lignin Features. Green and Sustainable Chemistry, 7, 114140.

https://doi.org/10.4236/gsc.2017.72010

Received: April 5, 2017

Accepted: May 19, 2017

Published: May 22, 2017

Copyright $\odot 2017$ by authors and Scientific Research Publishing Inc. This work is licensed under the Creative Commons Attribution International License (CC BY 4.0).

http://creativecommons.org/licenses/by/4.0/

\begin{abstract}
This study aims at investigating the impact of ionic liquid extraction on lignin structure by studying the mechanism of lignin depolymerization in 1-ethyl3-methylimidazolium acetate EMIM[OAc]) and comparing it with that of organosolv and milled wood methods. Ionic liquid mediated lignin (ILL) using EMIM[OAc]), ethanol organosolv lignin (EOL) and milled wood lignin (MWL) were isolated from Typha capensis (TC) and subjected to several analytical characterizations. Experimental data shows that ILL exhibited a relatively lower degree of condensation, lower aromatic C-C structures and a higher aliphatic $\mathrm{OH}$ with values of $0.42 / \mathrm{Ar}, 1.94 / \mathrm{Ar}$ and $1.33 / \mathrm{Ar}$ moieties compared with EOL values of $0.92 / \mathrm{Ar}, 2.22 / \mathrm{Ar}$ and $0.51 / \mathrm{Ar}$ moieties respectively. The ILL was depolymerized under mild conditions giving relatively higher $\beta$-aryl ether linkages content, higher molecular mass, and exhibited closer structures and reactivity to native lignin than EOL. These insights on TC lignin depolymerization in EMIM[OAc]) acetate may contribute to better value-addition of lignocellulosic biomass.
\end{abstract}

\section{Keywords}

1-Ethyl-3-Methylimidazolium Acetate, Ionic Liquid Lignin, Ethanol

Organosolv Lignin, Lignin Depolymerization, Milled Wood Lignin

\section{Introduction}

Lignocellulose fractionation using organic solvents is receiving a growing inter- 
est [1]. With organosolv pulping, a pulp with good enzymatic digestibility, but also high-quality lignin, can be obtained, allowing for multiple high value products [2] [3] [4]. More recently Ionic liquids (ILs) have also been used for biomass fractionation [5] [6] [7] [8] [9]. Among all the ILs used, EMIM [OAc] is particularly powerful, as the treatment conditions can be turned effectively to fractionate lignin and cellulose rich pulp from lignocellulosic biomass [5], and also collect intact cellulose nanocrystals [10] [11]. Additionally, EMIM [OAc] has interesting properties for a possible scale up: low toxicity (LD50 > $2000 \mathrm{mg} \cdot \mathrm{Kg}^{-1}$ ), low corrosiveness, a low melting point of less than $-20^{\circ} \mathrm{C}$, low viscosity $(10 \mathrm{mPa}$ $\mathrm{s}$ at $80^{\circ} \mathrm{C}$ ) and recyclability [5]. Therefore, in view of a biorefinery deliverables of several high value products, EMIM [OAc] is very interesting. However, the delignification chemistry of EMIM [OAc] and the resulting lignin structure is not fully understood.

EMIM [OAc] treatment led to high lignin solubility but low wood flour solubility, and also enabled the disruption of the chemical integrity and provided a lignin extraction yield of $4.4 \mathrm{~g} / \mathrm{kg}$ IL [6]. Furthermore, lignin extracted by EMIM [OAc] from poplar wood resulted in lower S/G ratio, reduction of molecular weight and more uniform fragments, compared to the MWL counterpart [12]. The functional-group, rather than the size of the anion of ILs, controls lignin fragmentation and the anion plays a much larger role in lignin depolymerization [13]. With EMIM [OAc] pretreatment of biomass, deacetylation of xylan and acetylation of lignin units occurs [14]; these processes contribute to swelling, followed by dissolution, disintegration and derivatization of wood [15].

While chemical and physico-chemical characterizations of ethanol organosolv lignin from different feedstocks have been widely reported, little work has been done in this regard for ionic liquids lignins from EMIM [OAc]. An earlier report by Kim et al. characterized EMIM [OAc] lignin from poplar, a wood plant, in comparison with the MWL [12]. Most other studies on ionic liquid for lignocellulosic fractionation emphasized identifying efficient ionic liquids and optimizing the conditions for increased delignification and improved enzymatic hydrolyzability of cellulose rich residues to fermentable sugar [5] [9] [16] [17] [18].

In the current report, the purpose is to study the chemical structure of lignin isolated by EMIM [OAc] IL from Typha capensis (an herbaceous plant) and compare it to the (1) well-known chemistry of ethanol organosolv lignin, and (2) milled wood lignin (MWL) structure, which is a reference point in lignin studies as lignin isolates closest to the intact lignin from the plant material. To that aim, lignins were extracted from Typha capensis using EMIM [OAc] and ethanol organosolv methods as well as the classical MWL method, and the isolated lignin samples were subjected to an array of analytical procedures, including high performance anion-exchange chromatography with pulsed amperometric detection (HPAE-PAD), elemental analysis, Fourier transform infrared (FT-IR), ${ }^{13} \mathrm{C}$ and ${ }^{31} \mathrm{P}$ nuclear magnetic resonance $\left({ }^{13} \mathrm{C} \&{ }^{31} \mathrm{P} \mathrm{NMR}\right)$, thermogravimetric analysis (TGA), gel permeation chromatography (GPC) and wet chemistry procedures for functional groups determination. 


\section{Experimental Methods}

\subsection{Materials}

1-ethyl-3-methylimdazolium acetate (EMIM [OAc]), ethanol, sulfuric acid, dimethyl sulfoxide (DMSO), ethyl acetate, n-hexane, tetrahydrofuran (THF), dichloromethane (DCM), 2-chloro-4,4,5,5-tetramethyl-1,3,2-dioxaphospholane (TMDP), pyridine, chloroform, and chromium III acetylacetonate were all purchased from Sigma Aldrich. All the chemicals were analytical grade and used as supplied.

Typha capensis sample was uprooted from canals in Kura village, Kano State, Nigeria. The protocol edited by Hames et al. [19], was used for sample preparation. The freshly harvested TC was cut to $\leq 2 \mathrm{~cm}$ and sun dried for 4 days, packed in cellophane and brought to Germany. Samples were further dried in an oven at $40^{\circ} \mathrm{C}$ for $48 \mathrm{~h}$, milled to obtain particle size $\leq 0.4 \mathrm{~mm}$ and designated as raw TC $\left(\mathrm{TC}_{\text {raw }}\right)$. The $\mathrm{TC}_{\text {raw }}$ was sequentially and exhaustively extracted using a Soxhlet Extraction apparatus with water, ethanol and dichloromethane (DCM), refluxed for $16 \mathrm{~h}, 16 \mathrm{~h}$ and $8 \mathrm{~h}$ respectively to obtain extractive free $\mathrm{TC}\left(\mathrm{TC}_{\text {extracted }}\right)$, and kept until further use [20]. 3 lignin isolation methods were performed, Figure 1.

\subsection{Methods}

\subsubsection{MWL Isolation}

The procedure by Bjorkman as modified by Obst and Kirk [21] and Rencoret et al. [22] was used to process MWL from TC [21] [22]. Details are provided in supplementary information.

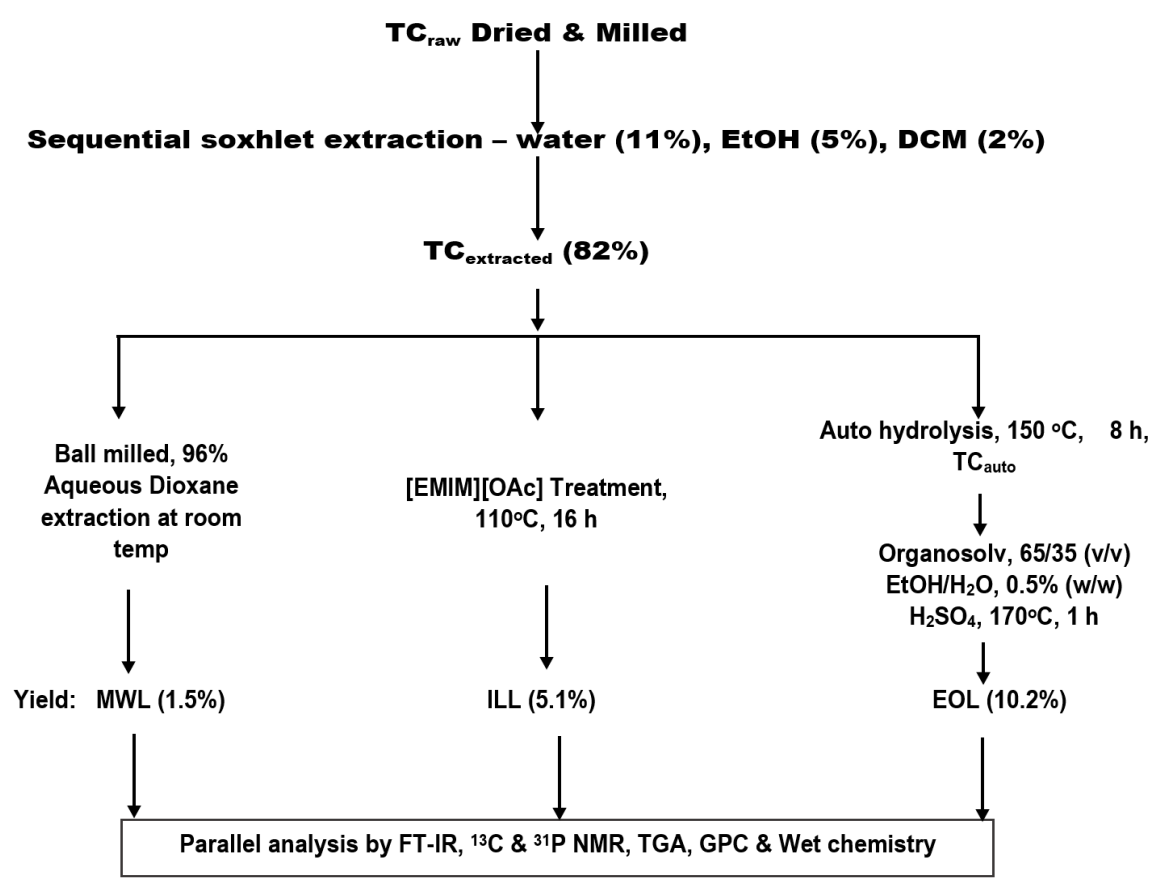

Figure 1. Experimental scheme for TC lignins isolation and characterization.Key: TC = Typha capensis, $\mathrm{TC}_{\text {raw }}=\mathrm{Raw} \mathrm{TC}$, TCextracted $=$ Extractive free TC; $\mathrm{TC}_{\text {auto }}=$ Autohydrolyzed TC; $\mathrm{MWL}=$ milled wood lignin; $\mathrm{EOL}=$ ethanol organosolv lignin; ILL = ionic liquid lignin; [EMIM] [OAc] = 1-ethyl-3-methylimidazoluim acetate; DCM = dichloromethane; $\mathrm{EtOH}=$ ethanol. 


\subsubsection{Ionic Liquid Mediated Lignin Extraction}

The procedure published by Sun et al. with slight modification was used [5]. Briefly, $1 \mathrm{~g}$ of $\mathrm{TC}_{\text {extracted }}$ was weighed in a $100 \mathrm{~mL}$ conical flask and $20 \mathrm{~g}$ of 1-ethyl-3-methylimidazolium acetate was added and reacted at $110^{\circ} \mathrm{C}$ in an oil bath with magnetic stirring for $16 \mathrm{~h}$. The reactant was cooled to room temperature and poured into a $400 \mathrm{~mL}$ beaker containing $150 \mathrm{~mL}$ acetone/water (1:1, $\mathrm{v} / \mathrm{v}$ ) solution and briskly stirred with a tuning fork. The precipitated cellulose rich residue was separated by filtration through Whatman filter paper using a Buchner funnel under reduced pressure. The residue was washed 3 times with 50 $\mathrm{mL}$ of acetone/water solution and filtered again. All the filtrates were joined together, placed in an open beaker and magnetic stirred overnight under the fume hood to evaporate the acetone. The liquid fraction containing lignin, water and IL was cooled overnight in a refrigerator at $4^{\circ} \mathrm{C}$ and lignin was separated by centrifugation at $4700 \mathrm{rpm}$ for 20 minutes. The lignin was lyophilized and then oven dried overnight at $40^{\circ} \mathrm{C}$. With the IL being recyclable, water in the liquid fraction could be evaporated to recover IL under reduced pressure for recycling. $\mathrm{Pu}$ rification step was performed by Soxhlet extraction of this lignin using ethanol, ethyl acetate and $\mathrm{n}$-hexane refluxed for $8 \mathrm{~h}$ sequentially [23] but was not efficient. Washing with $0.1 \mathrm{M} \mathrm{HCl}$ was more effective in obtaining a relatively pure ILL.

\subsubsection{Autohydrolysis Pretreatment and Sulfuric Acid Catalyzed Ethanol Organosolv Lignin Extraction}

Autohydrolysis was performed as follows: $20 \mathrm{~g}$ dry matter of the $\mathrm{TC}_{\text {extracted }}$ sample was loaded into a $0.6 \mathrm{~L}$ stainless steel pressure Parr reactor equipped with Parr 4842 temperature controller (Parr Instrument Company, Moline IL) and was supplemented with deionized water to a solid to liquid ratio of 1:9. Content was reacted at $150^{\circ} \mathrm{C}$ with continuous stirring for $8 \mathrm{~h}$, after which it was quenched in ice water. The liquid phase was separated by filtration using Whatman filter paper no. 4. The solid residue was washed with hot water, ca $70^{\circ} \mathrm{C}(3 \times 50 \mathrm{~mL})$. The recovered autohydrolyzed residue $\left(\mathrm{TC}_{\text {auto }}\right)$ was oven dried at $40^{\circ} \mathrm{C}$.

For the ethanol organosolv lignin isolation, the oven dried $\mathrm{TC}_{\text {auto }}$ sample was weighed and loaded into the Parr reactor and an ethanol/water solution-65:35 $(\mathrm{v} / \mathrm{v})$ containing $0.5 \%$ sulfuric acid $(\mathrm{w} / \mathrm{w})$ - was added to obtain a solid to liquid ratio of 1:9. The mixture was then reacted at $170^{\circ} \mathrm{C}$ for $1 \mathrm{~h}$. After cooling at the end of the reaction, the solid phase was recovered by filtration using Whatman filter paper number 4 and the residue was washed three times using warm $\left(60^{\circ} \mathrm{C}\right)$ ethanol/water $(4: 1 \mathrm{ratio}, \mathrm{v} / \mathrm{v})$ at a volume of ca $2 \mathrm{~mL}$ per gram of pretreated sample. The filtrates were combined and deionized water added. The mixture was cooled overnight in a refrigerator at $4^{\circ} \mathrm{C}$ then centrifuged at 4700 rpm for 20 minutes to precipitate the ethanol organosolv lignin (EOL). The recovered EOL was further washed with deionized water and oven dried at $40^{\circ} \mathrm{C}$ for approximately 12 hours.

\subsubsection{Lignin Content and Composition Analysis}

A two-stage sulfuric acid hydrolysis procedure was performed to determine the 
Klason lignin of $\mathrm{TC}_{\text {raw }}$, $\mathrm{TC}_{\text {extracted, }}$, and that of the isolated lignins, followed by monosaccharide analysis of the hydrolysate. Monosaccharide contents were analyzed by HPAE-PAD (ICS-3000 Dionex) equipped with a Dionex CarboPacTM PA-20 guard column $(3 \times 30 \mathrm{~mm})$ attached with a Dionex CarboPacTM PA-20 $(3 \times 150 \mathrm{~mm})$ analytical column. Filtered samples $(20 \mu \mathrm{L})$ were eluted at $35^{\circ} \mathrm{C}$ and at $0.4 \mathrm{~mL} / \mathrm{min}$ with the following composition: pure water $99.2 \% / 250$ $\mathrm{mM} \mathrm{NaOH}$ 0.8\%: 0 - 20 min; pure water 75\%/250 mM NaOH 20\%/NaOAc (1 M)- $\mathrm{NaOH}$ (20 mM) 5\% 20 - $37 \mathrm{~min}$; pure water 40\%/250 mM NaOH 20\%/ $\mathrm{NaOAc}(1 \mathrm{M})-\mathrm{NaOH}(20 \mathrm{mM}) 40 \% 37$ - $41 \mathrm{~min}$; each elution was followed by a wash and subsequent equilibration time. External sugar and uronic acids standards were used for calibration (7 points per curve; fructose, glucose, xylose, galactose, mannose, rhamnose, arabinose, galacturonic acid and glucuronic acid -all purchased from Sigma-Aldrich). In addition to impurities identified in the sugar analysis of hydrolysates, nitrogen and sulfur from elemental analysis were also identified as impurity.

\subsubsection{Fourier Transform Infrared Spectroscopy (FT-IR)}

Infrared spectra were acquired from FT-IR spectrometer 65 (Perkin Elmer, USA) in transmittance mode of 64 scans, resolution of $4 \mathrm{~cm}^{-1}$ spanning 4000 to $400 \mathrm{~cm}^{-1}$ band using $\mathrm{KBr}$ pellets containing $1 \%$ of finely ground sample. Baseline correction and normalization was done with a zero baseline taken from a common point at $1900 \mathrm{~cm}^{-1}$ and with a maximum range of $4000-900 \mathrm{~cm}^{-1}$. An internal standard was selected by having bands normalized as a ratio of each absorbance to the absorbance at $1510 \mathrm{~cm}^{-1}$ [24] [25]. The selected band at 1510 $\mathrm{cm}^{-1}$ is assigned as reference, being a typical stretching of aromatic rings which has relatively constant intensity [24].

\subsubsection{TGA}

Thermogravimetric analysis was conducted using Pyris 1 (Perkin Elmer, USA) and heated from $20^{\circ} \mathrm{C}$ to $900^{\circ} \mathrm{C}$ at the rate of $10^{\circ} \mathrm{C} \mathrm{min}^{-1}$ under constant air flow.

\subsection{7. ${ }^{13} \mathrm{C}$ and ${ }^{31} \mathrm{P}$ NMR}

Quantitative solution state ${ }^{13} \mathrm{C}$ and ${ }^{31} \mathrm{P}$ NMR analysis were conducted on a Bruker Avance-400 NMR spectrometer and the data was analyzed using 3.2 topspin Bruker software. $150 \mathrm{mg}$ of the sample was dissolved with slight heating and stirring in $0.38 \mathrm{~mL}$ DMSO-d6 and $20 \mu \mathrm{L}$ of $0.25 \mathrm{mg} / \mathrm{mL}$ chromium acetylacetonate in DMSO-d6 as a relaxation agent and placed in an NMR tube to acquire ${ }^{13} \mathrm{C}$ NMR data.

Phosphorus NMR used inverse-gated decoupling (Walzt-16) pulse sequence to avoid the Nuclear Overhauser effect (NOE). Sample preparation used 2chloro-4,4,5,5-tetramethyl-1,3,2-dioxaphospholane (TMDP) as a phosphitilating reagent. The method outlined by Granata and Argyropoulos was applied [26]. Between 24 - $25 \mathrm{mg}$ of dried samples were each dissolved in $400 \mu \mathrm{L}$ solvent mixture of pyridine/chloroform $(1.6 / 1 ; \mathrm{v} / \mathrm{v})$ and $150 \mu \mathrm{L}$ of $3.6 \mathrm{mg} / \mathrm{mL}$ chromium III 
acetylacetonate (relaxation agent), $4.0 \mathrm{mg} / \mathrm{mL}$ cyclohexanol (internal standard) solution in pyridine/chloroform solvent mixture was added and vigorously stirred to dissolve. The phosphitylation reaction has been observed to be unstable, therefore, addition of the TMDP $(50 \mu \mathrm{L})$ was done just at the start of the NMR experiment.

\subsubsection{GPC}

The molecular-average weights were determined by gel permeation chromatography (GPC). Samples were first acetylated using aceto-bromination [27]. Briefly, a $10 \mathrm{mg}$ sample was weighed in a $50 \mathrm{~mL}$ round bottom flask and $2.3 \mathrm{~mL}$ of acetic anhydride was added. The content was reacted at room temperature with magnetic stirring for two hours. $0.25 \mathrm{~mL}$ of acetyl bromide was then added and stirring continued for two hours. Acetic anhydride and acetyl bromide were evaporated using rotary evaporator. The acetylated samples were then freeze dried then dissolved in tetrahydrofuran (THF) at concentration of $4 \mathrm{mg} / \mathrm{ml}$. The solution was filtered using a syringe filter (PTFE, $0.45 \mu \mathrm{m}$ pore size). Samples were injected into the GPC system at a flow rate of $1 \mathrm{~mL} / \mathrm{min}$ at $22.5^{\circ} \mathrm{C}$ and 280 $\mathrm{nm}$ wavelength using THF as an eluent. The GPC system used includes an isocratic pump, a preparative autosampler, a UV detector and an SDV column combination. Data was acquired using narrow standard polystyrene calibration standard [27].

\subsubsection{Functional Groups Determination Using Wet Chemistry Procedure} To provide complementing information, established wet chemistry procedures for functional groups determination were applied to obtain the methoxy, carbonyl, carboxyl, phenolic and aliphatic hydroxyl contents of the lignin isolates [28] [29] [30] [31] [32]. As proof of the methoxy and carbonyl methods, vanillin was analyzed alongside each method. No significant differences between experimental and theoretical values were found for vanillin in each method, indicating the robustness of these procedures. Benzoic acid was used as a blank to prove the presence of phenolic $\mathrm{OH}$ and carboxyl group. A detailed procedure for determination of the functional groups is provided in supplementary documents.

\section{Results}

\subsection{Process Efficiency and Samples Compositions}

Table 1 depicts the compositions of raw $\mathrm{TC}\left(\mathrm{TC}_{\text {raw }}\right)$, extractive free $\mathrm{TC}\left(\mathrm{TC}_{\text {ex }}\right.$ tracted) and the lignins - MWL, ILL and EOL, determined by two stage sulfuric acid hydrolysis and sugar analysis of the resulting hydrolysates using HPAE-PAD. $\mathrm{TC}_{\text {raw }}$ consists of $18 \%$ extractives and structural components include $39 \%$ glucan, $19 \%$ hemicellulose sugars (xylan, arabinose, fructose, rhamnose, mannose) and $23 \%$ lignin, (Table 1(a)). Other components in small quantities include galacturonic and glucuronic acids. Carbon, hydrogen, nitrogen and sulfur content were determined using elemental analysis procedure, oxygen values were obtained by differences, results in supplementary document as Table S1. EOL had 
Table 1. Composition of raw \& extractive free TC and lignin isolates. Values in $\mathrm{g} / 100 \mathrm{~g}$ biomass (\%), dry basis. (a) Composition of raw TC; (b) Extractive free and lignin isolates composition.

(a)

\begin{tabular}{cccccc}
\hline & Extractives & \multicolumn{3}{c}{ Structural components } \\
\hline $\mathrm{H}_{2} \mathrm{O}$ Soluble & EtOH Soluble & DCM Soluble & Glucan & Hemicellulose & Lignin \\
\hline $11.0 \pm 0.5$ & $5.0 \pm 0.2$ & $2.0 \pm 0.1$ & $39.0 \pm 3.4$ & $19.0 \pm 1.1$ & $23.0 \pm 1.2$ \\
\hline
\end{tabular}

(b)

\begin{tabular}{ccccc}
\hline Parameter & TC $_{\text {extracted }}$ & MWL & ILL & EOL \\
\hline Lignin Yield & ${ }^{\mathrm{a} 24.0 \pm 1.4}$ & $1.5 \pm 0.4$ & $5.1 \pm 0.5$ & $10.2 \pm 0.2$ \\
Lignin content (KL) & $24.0 \pm 1.4$ & $89.0 \pm 1.6$ & $93.0 \pm 1.5$ & $90.0 \pm 2.2$ \\
Glucose & $49.0 \pm 1.6$ & $2.0 \pm 0.2$ & $0.6 \pm 0.1$ & $0.2 \pm 0.0$ \\
HS & $22.6 \pm 1.4$ & $5.5 \pm 0.6$ & $6.1 \pm 0.1$ & NG \\
GalU & $1.8 \pm 0.1$ & $0.1 \pm 0.0$ & NG & NG \\
GlcU & $2.1 \pm 0.0$ & $0.5 \pm 0.0$ & $0.6 \pm 0.1$ & NG \\
\hline
\end{tabular}

Key: $\mathrm{TC}_{\text {raw }}=$ Raw $\mathrm{TC}, \mathrm{TC}_{\text {extracted }}=$ Extractive free $\mathrm{TC}, \mathrm{KL}=$ Klason lignin, a' aield indicates total lignin in $\mathrm{TC}_{\text {extracted }}, \mathrm{HS}=$ Hemicellulose sugars, $\mathrm{GalU}=$ Galacturonic acid, $\mathrm{GlcU}=$ Glucuronic acid, $\mathrm{NG}=$ negligible .

the least values of impurities compared to ILL and MWL, Table 1(b). Elemental analysis of the lignin samples reveals that there are no significant differences in values of carbon and hydrogen for the 3 samples.

However, ILL had significantly high values of nitrogen, while $2 \%$ sulfur was detected in EOL compared to $0 \%$ in MWL and ILL and $0.4 \%$ in the extractive free TC.

Yields of lignin extraction in this study reflect the extent of the disruption of the chemical integrity of the TC system and solubilisation of lignin, with the highest yield obtained from a more severe reaction conditions (temperature and acid catalysis) [33]. The mild reaction condition of MWL had the lowest yield of $1.5 \%$ followed by the ILL with a value of $5 \%$, extracted at $110^{\circ} \mathrm{C}$, while the highest yield of $10 \%$ was obtained from the EOL process, extracted at $170^{\circ} \mathrm{C}$ under dilute sulfuric acid catalyst, Table 1(b). Low yield of the MWL has been an issue, especially with herbaceous plant materials like TC, so the values agree with literature [34].

\subsection{Structural Characterization of Lignin Fractions}

\subsubsection{FT-IR Spectra}

FT-IR full spectra are presented in Figure 2(a) and band assignments are presented as supplementary documents in Table S2 based on previous publications [24] [35] [36]. The expanded region of interest of the FT-IR spectra for the 3 lignin isolates is portrayed in Figure 2(b), highlighting key differences revealing changes in isolation mechanisms.

The band at $1729 \mathrm{~cm}^{-1}$ assigned to alcoholic acetate carbonyl was observed in the MWL but absent in both EOL and ILL, indicating extensive ester hydrolysis 

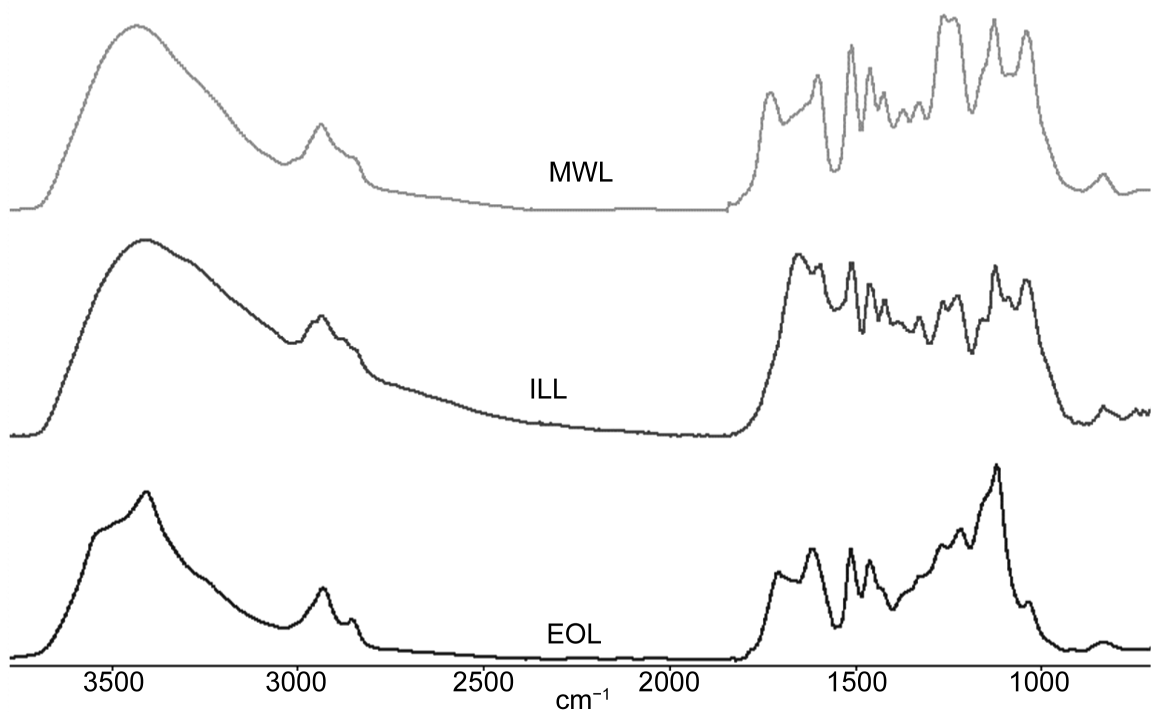

(a)

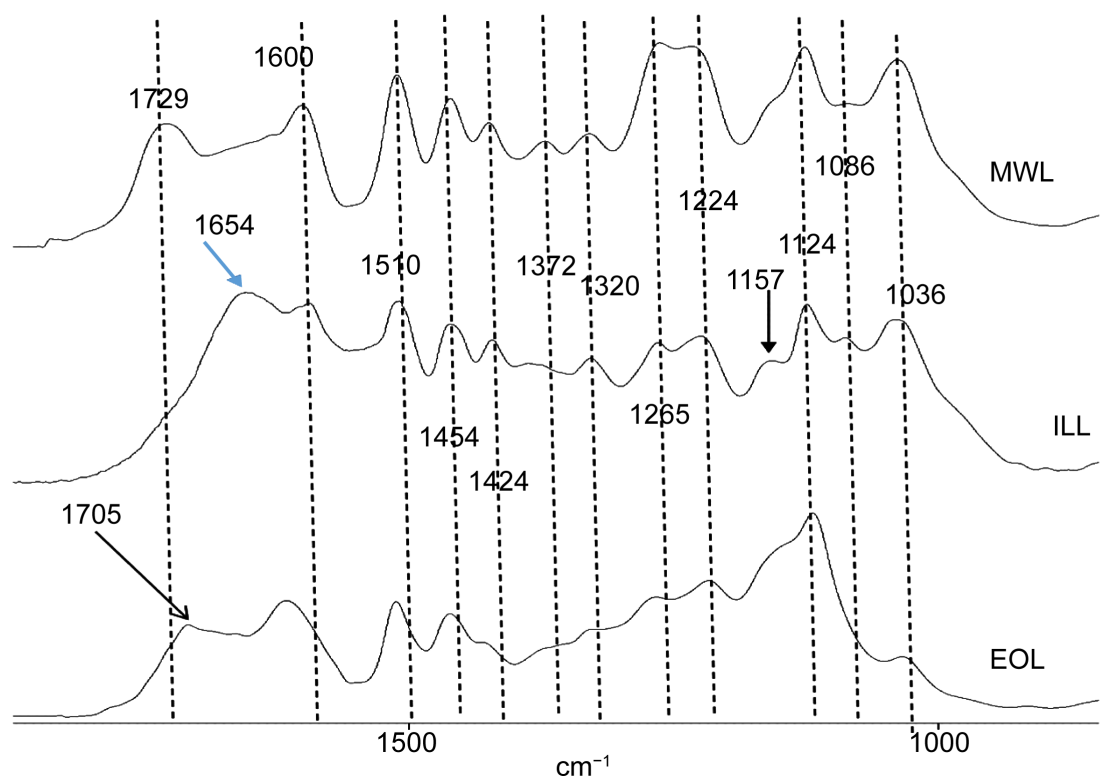

(b)

Figure 2. FTIR Spectra: (a) Full spectra of the three lignin isolates, (b) Exploded view of the lignin isolates from Typha capensis (MWL, ILL and EOL), revealing key structural differences.

in EOL and ILL. The presence of acetate carbonyl in MWL also reveals that natural acetylation of TC was preserved. This was confirmed by the same absorbance in the extractive free TC (result not presented). Natural acetylation of TC agrees with literature, as lignins and hemicelluloses from herbaceous plants have been observed to be naturally acetylated [37] [38]. An absorbance at $1705 \mathrm{~cm}^{-1}$ observed in EOL reveals carbonyl, a hydrolysis product of the $\beta$-O-4 ether cleavage. This band is assigned to ketone groups arising from dehydration reactions occurring at the lateral chain of lignin under harsh conditions, and indeed a clear indication of the occurrence of Hibbert's ketones [33] [39]. At bands 1036 
$\mathrm{cm}^{-1}$, associated to C-O stretching of primary alcohols, and $1086 \mathrm{~cm}^{-1}$, assigned to $\mathrm{C}-\mathrm{O}$ deformation in secondary alcohols and aliphatic ethers, higher intensities were observed for MWL > ILL > EOL, indicating more primary and secondary alcohols in that order. These bands are also indicative of the differences in carbohydrate contents or polysaccharide impurities, with EOL having the least value [40] [41].

\subsection{2. ${ }^{13} \mathrm{C},{ }^{31} \mathrm{P}$ NMR}

Further structural properties of the lignin isolates were studied via ${ }^{13} \mathrm{C}$ and ${ }^{31} \mathrm{P}$ NMR. The broad acquisition spectrum and quantitative option of ${ }^{13} \mathrm{C} \mathrm{NMR}$ presents the opportunity to acquire more structural components and bonding information, and the quantification of the various functional groups. Figure 3 and Figure 4 show ${ }^{13} \mathrm{C}$ NMR spectra of the acetylated lignin isolates and the expanded aromatic region. In the aromatic region (162 - $103 \mathrm{ppm})$, the signals of the residues of syringyl (153.8 ppm, 105 ppm), p-hydroxyphenyl (130 ppm, 121 ppm) and guaiacyl $(151,136,120,119,112 \mathrm{ppm})$ indicate that the lignin species are SGH type, as expected. However, compared to ILL and EOL, higher concentration of G-residue was observed in the MWL implied by more intense signals of the guaiacyl residue. The presence of ferulic acid was reflected by signals at 169.0 (CO) and $127.3 \mathrm{ppm}(\mathrm{C}-1)$ in all the 3 lignin isolates with a signal at 111.6 (C-2), peculiar to MWL and ILL, while signals at 148.8 (C-3) and 150 (C-4) ppm were only observed in MWL. The various structural groups were estimated by integration of the regions of interest, referenced to the aromatic region (160 - 103 ppm), where a value of 6.12 was taken to represent the six aromatic carbons and a contribution of 0.12 per 100 aromatic units from side-chain carbons of coniferic and coumaric moieties. Thus, the integral value divided by 6.12 is equivalent to

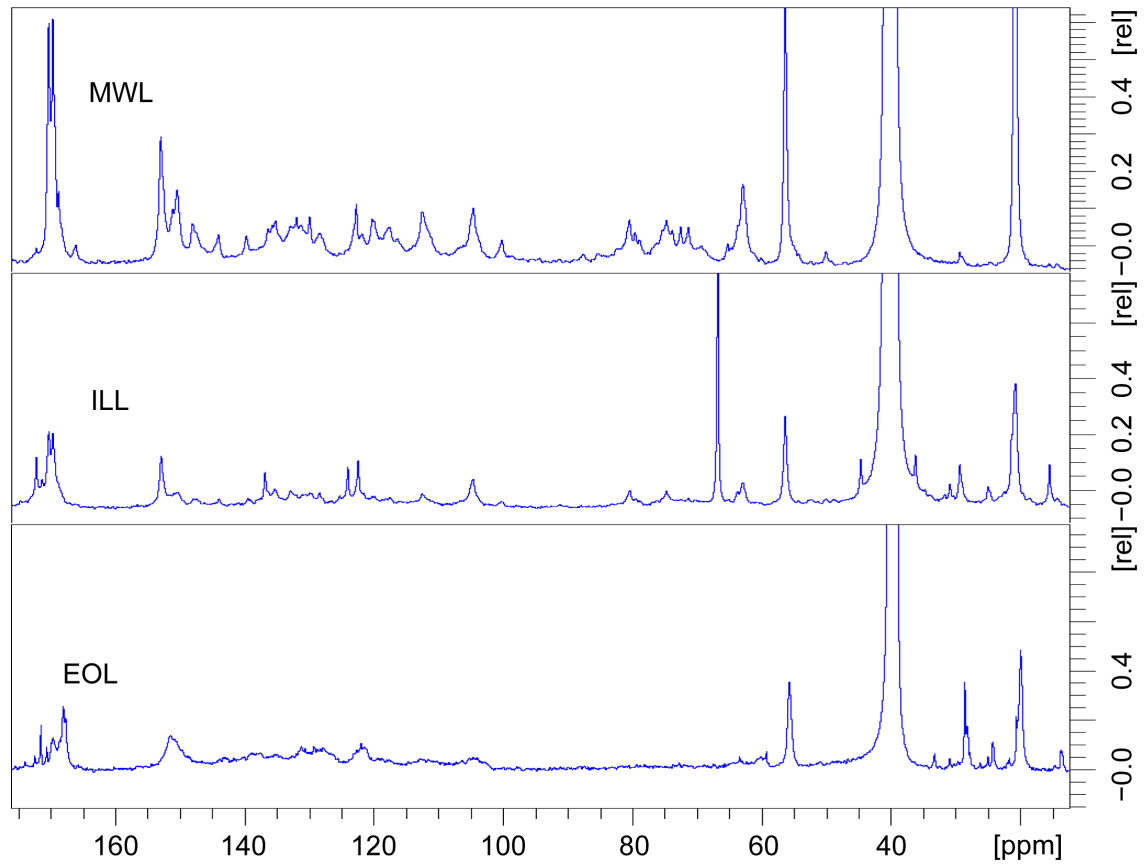

Figure $3 .{ }^{13} \mathrm{C}$ Spectra of acetylated lignin isolates. 


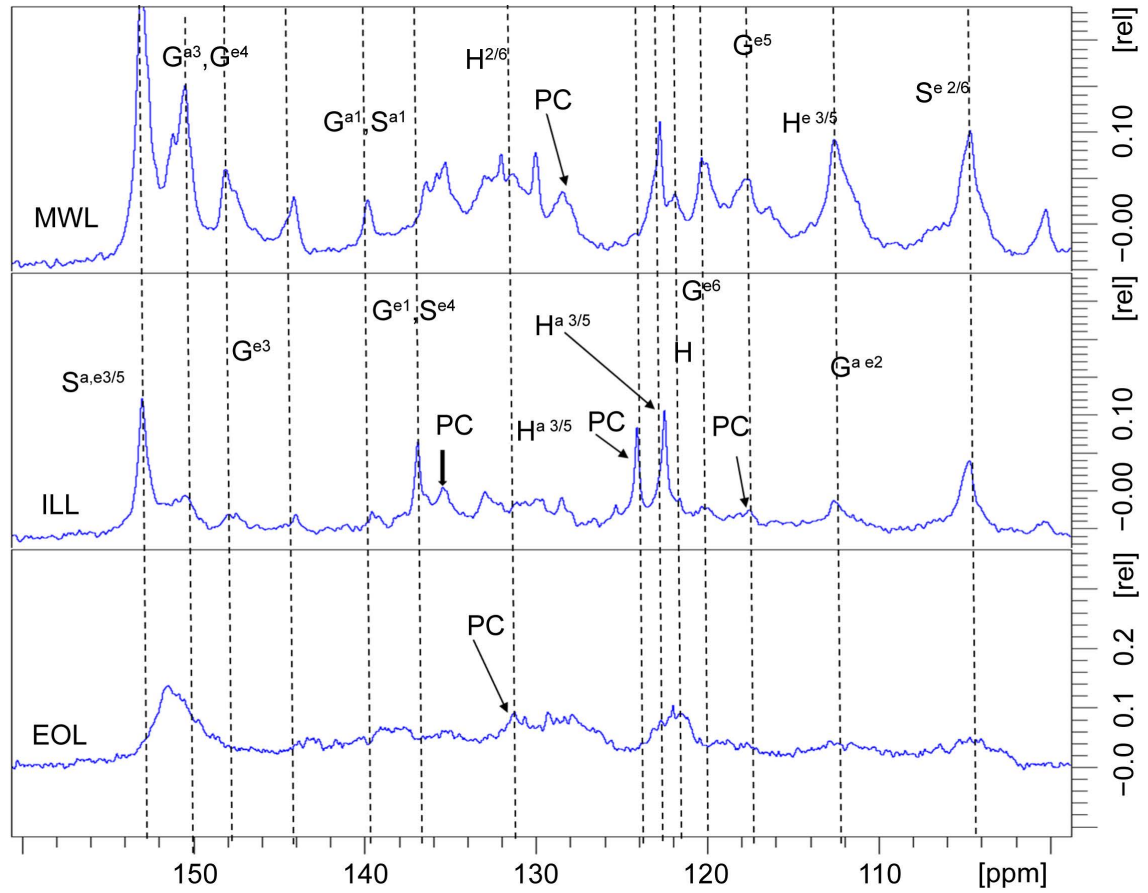

Figure 4. Expanded aromatic region of ${ }^{13} \mathrm{C}$ spectra of acetylated lignin isolates: $\mathrm{S}=$ syringyl, $\mathrm{G}=$ guaiacyl, $\mathrm{H}=$ p-hydroxyphenyl, $\mathrm{PC}=\mathrm{p}$-coumaric acid, $\mathrm{e}=$ etherified, $\mathrm{a}=$ acetylated.

one aromatic ring (Ar) [42] [43]. Values in Table 2 indicate higher values of aromatic C-C structures (2.22/Ar) and phenolic $\mathrm{OH}$ (0.59/Ar), but lower aliphatic $\mathrm{OH}$ (0.51) moieties in EOL compared to the corresponding values for ILL (1.94/Ar, 0.38/Ar and 1.34/Ar) and MWL (1.78/Ar, 0.31/Ar and 0.97/Ar). A lower $\mathrm{C}-\mathrm{O}$ bond was observed in ILL compared to EOL, which also correlates with lower $G$ units in ILL since the $S$ units normally have a higher number of $\mathrm{C}-\mathrm{O}$ bonds than $\mathrm{H}$ and $\mathrm{G}$ units. A higher $\mathrm{S}$ unit in EOL was further validated in the $S / G$ ratio determined by ${ }^{31} \mathrm{P}$ NMR. The degree of condensation was estimated using the integrals in the region $125-103$ ppm, assuming that uncondensed herbaceous plant lignin will contain three protonated aromatic carbons per aromatic ring. Therefore, three minus the integration of the region (125 $203 \mathrm{ppm}$ ) yields the degree of condensation [43]. A significant difference in the degree of condensation was observed, with EOL having a leading value of 0.92/Ar compared to $0.42 / \mathrm{Ar}$ in ILL and 0.58/Ar in MWL. Further information on the carbon-carbon bond structures were observed in the intense signals of MWL > ILL at $72.0 \mathrm{ppm}$ (C- $\alpha$ in $\beta$-O-4' G and S erythro), $70.8 \mathrm{ppm}$ (C- $\alpha$ in $\beta$-O-4' G and S threo) and $61.5 \mathrm{ppm}(\mathrm{C}-\gamma$ in $\beta$-O-4' $\mathrm{G}$ and $\mathrm{S}$ threo and erythro) associated with resonances of $\mathrm{C}-\alpha$ and $\mathrm{C}-\gamma$ in $\beta$-O-4 linkages, [44]. This reveals that a higher proportion of $\beta$-aryl ether structures were preserved in the order of mild conditions.

Quantitative ${ }^{31} \mathrm{P}$ NMR enabled the determination of the hydroxyl functional groups, spectra in Figure 5. Values of the hydroxyl functional groups obtained from the integration of the respective regions using the cyclohexanol peak as 
Table 2. Functional groups data. (a) Determined from spectral regions of ${ }^{13} \mathrm{C} N M R$; (b) Determined from spectral regions of ${ }^{31} \mathrm{P}$ NMR; (c) Determined by wet chemistry procedure.

(a)

\begin{tabular}{|c|c|c|c|c|}
\hline \multirow{2}{*}{$\underline{\text { Structure }}$} & \multirow{2}{*}{$\frac{\text { Chemical shift }}{\underline{\text { range }(\mathrm{ppm})}}$} & \multicolumn{3}{|c|}{ No. of Moieties/Aromatic Ring } \\
\hline & & MWL & ILL & EOL \\
\hline Methoxy content & $57-54$ & 0.83 & 0.74 & 0.73 \\
\hline Aromatic methine carbons & $125-103$ & 2.42 & 2.58 & 2.08 \\
\hline Aromatic C-C structures & $141-125$ & 1.78 & 1.94 & 2.22 \\
\hline Oxygenated aromatic carbons & $160-141$ & 1.86 & 1.67 & 1.78 \\
\hline Phenolic $\mathrm{OH}$, conjugated $\mathrm{COOR}$ & $168.6-166$ & 0.31 & 0.38 & 0.59 \\
\hline Secondary aliphatic $\mathrm{OH}$ & $169.6-168.6$ & 0.61 & 0.67 & 0.24 \\
\hline Primary aliphatic $\mathrm{OH}$ & $172-169.6$ & 0.36 & 0.67 & 0.27 \\
\hline Degree of condensation ${ }^{\mathrm{a}}$ & $125-103$ & 0.58 & 0.42 & 0.92 \\
\hline
\end{tabular}

(b)

\begin{tabular}{cccccc}
\hline \multirow{2}{*}{ Structure } & $\begin{array}{c}\text { Chemical shift } \\
\text { range (ppm) }\end{array}$ & $\underline{3} \underline{\text { mmol/g lignin }}$ \\
\cline { 5 - 6 } & Aliphatic OH & $150-145$ & $\underline{\text { ILL }}$ & $\underline{\text { EOL }}$ \\
Syringyl OH & $144.5-140.5$ & & 0.39 & 0.31 & 1.24 \\
Guaiacyl OH & $140.5-138.5$ & & 0.48 & 0.2 & 0.73 \\
p-hydroxyphenyl OH & $138.5-136.5$ & 0.45 & 0.2 & 0.38 \\
Carboxylic & $135-133$ & 0.16 & 0.12 & 0.21 \\
\hline
\end{tabular}

(c)

\begin{tabular}{cccc}
\hline & \multicolumn{3}{c}{$\underline{\text { mmol/g lignin }}$} \\
\hline Functional group & $\underline{\text { MWL }}$ & $\underline{\text { LL }}$ & $\underline{\text { EOL }}$ \\
\hline Methoxy & $4.3 \pm 0.0$ & $2.9 \pm 0.0$ & $4.2 \pm 0.0$ \\
Carbonyl & $1.5 \pm 0.0$ & $0.2 \pm 0.1$ & $3.0 \pm 0.1$ \\
Carboxyl & $0.8 \pm 0.0$ & $0.5 \pm 0.0$ & $1.1 \pm 0.1$ \\
Phenolic OH & $1.5 \pm 0.9$ & $1.5 \pm 0.1$ & $2.4 \pm 0.1$ \\
Aliphatic OH & $2.5 \pm 0.5$ & $5.1 \pm 0.1$ & $2.2 \pm 0.1$ \\
\hline
\end{tabular}

${ }^{\text {a }}$ Calculated from 3-I $\mathrm{I}_{125-103}$.

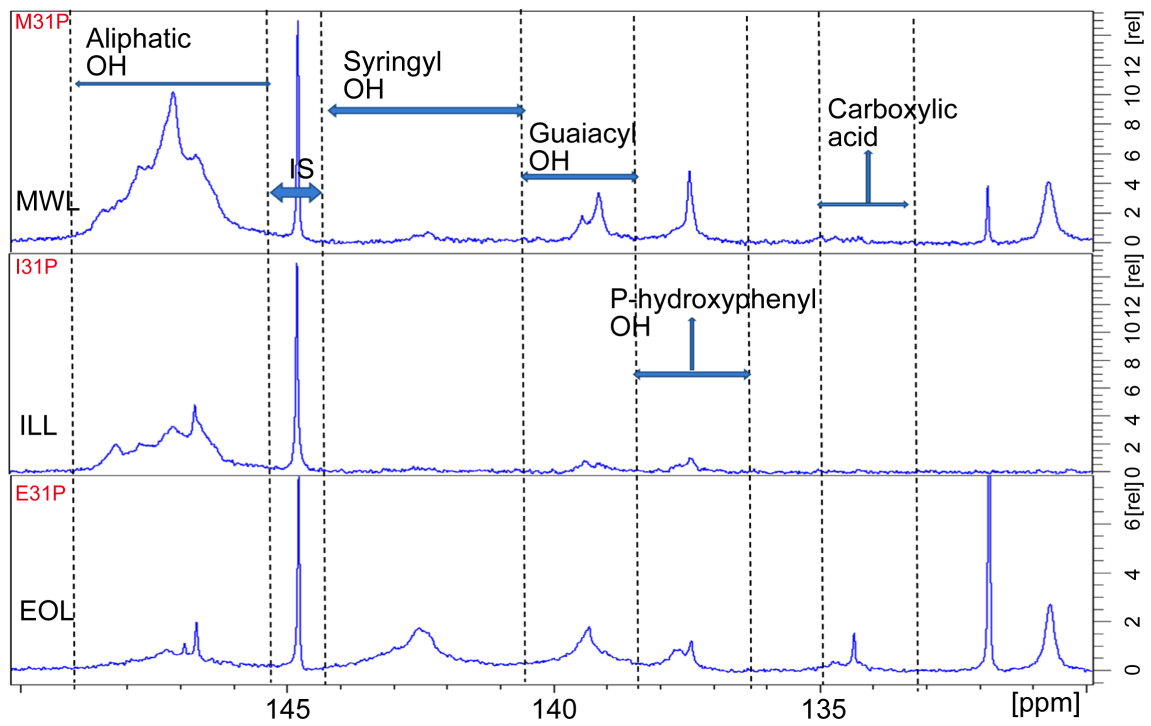

Figure $5 .{ }^{31} \mathrm{P}$ NMR spectra of the lignin isolates. 
reference is in Table 2. Further evidence of the lateral chain dehydration reaction was seen in values of aliphatic hydroxyl, where EOL had the lowest values, implying that it was more depolymerized. An intense syringyl $\mathrm{OH}$ signal around $142.8 \mathrm{ppm}$ was observed in EOL, giving a value of $1.08 \mathrm{mmol} / \mathrm{g}$ lignin, compared to values of $0.86 \mathrm{mmol} / \mathrm{g}$ and $0.50 \mathrm{mmol} / \mathrm{g}$ lignin in MWL and ILL respectively. The S:G:H abundance determined by this method are 30:36:34 (MWL), 43:28:28 (ILL) and 53:31:16 (EOL), giving S/G ratios of 0.87, 1.19 and 1.24 for the MWL, ILL and EOL in that order. The H unit values in the order MWL $>$ ILL $>$ EOL imply increasing hydrolysis of p-coumarate, which is in the order of hash conditions.

\subsubsection{Functional Groups by Wet Chemistry Process: Comparison with Data from NMR}

Table 2(c) shows values of the functional groups obtained from wet chemistry procedures. In comparison to ${ }^{13} \mathrm{C}$ and ${ }^{31} \mathrm{P} \mathrm{NMR}$, the phenolic $\mathrm{OH}$ yielded the closest absolute values between the methods in each sample. However, significant variation was observed for aliphatic $\mathrm{OH}$, especially for ILL, where wet chemistry procedures gave a value of $5.1 \mathrm{~g} / \mathrm{mol}$, compared to the value of $1.55 \mathrm{~g} / \mathrm{mol}$ by quantitative ${ }^{31} \mathrm{P}$ NMR. Carboxyl values were generally higher in wet chemistry compared to NMR. Carboxyl groups have the lowest value of all the functional groups determined in all the 3 lignin species, examined in both wet and ${ }^{31} \mathrm{P}$ NMR methods. This agrees with literature, as several structural studies indicate that carboxyl groups in native lignin exist in extremely low concentration [30] [45]. Significant variation in carbonyl content was observed in this order EOL > MWL > ILL, with values of 3.0, 1.5 and $0.2 \mathrm{~m} \cdot \mathrm{mol} \cdot \mathrm{g}^{-1}$ lignin respectively, obtained only by wet chemistry procedures. This result indicates significant cleavage of $\alpha$ - and $\beta$-aryl ether bonds in EOL much more than in MWL \& ILL. Geiger and Fuggerer demonstrated the formation of $\mathrm{C}=\mathrm{O}$ containing structures from etherified p-hydrocinnamyl alcohol substructures during lignin treatment with phloroglucinol in concentrated $\mathrm{HCl}$ acid [46]. In addition to cinnamaldehyde type conjugated carbonyls, spruce MWL was found to contain conjugated carbonyl and possibly non-conjugated ( $\alpha$-carbonyl) groups as well as quinone keta structures [47].

We observed obvious differences in aliphatic $\mathrm{OH}$ between the NMR and the wet the chemistry procedure for ILL. The acetylation and hydrolysis reactions involved in the wet chemistry used to determine aliphatic $\mathrm{OH}$ may have proceeded in more than one way due to the numerous types of structural elements in ILL [44].

\subsubsection{Molecular Weight Distribution Analysis GPC}

Table 3 shows the weight average $(\mathrm{Mw})$, the number average $(\mathrm{Mn})$ molecular weights and the polydispersity index $(\mathrm{Mw} / \mathrm{Mn})$ of the 3 lignin isolates estimated from the GPC curves using polystyrene as a calibration standard and observed by the UV detector. The GPC curves are presented under supplementary documents as Figure S1. Based on the results, the EOL species is more depolymerized 
with molecular weights, in the order EOL < ILL < MWL. Also, EOL had a more narrowed molecular distribution, with the lowest polydispersity index value of 1.7 , followed by the ILL, with a value of 1.9 , while the MWL recorded a broader molecular distribution, with a value of 2.8 .

\subsubsection{Thermo-Physical Properties}

Thermo-physical properties were analyzed by the thermal degradation of lignin isolates, conducted under air atmospheres to achieve maximum degradation, Figure 6(a) and Figure 6(b). Results revealed a peak at the range of $80^{\circ} \mathrm{C}$ $180^{\circ} \mathrm{C}$ corresponding to moisture elimination. This was followed by two broad peaks: between $200^{\circ} \mathrm{C}-400^{\circ} \mathrm{C}$, during which cleavage of the functional groups and formation of lower molecular weight products occur, then at the temperature range of $440^{\circ} \mathrm{C}-630^{\circ} \mathrm{C}$, where the structural arrangement of products occur, followed by a long tail beyond $700^{\circ} \mathrm{C}$. Various oxygen functional groups and many aromatic rings, with various branches and activity of chemical bonds in lignins exhibit differing thermal stability, thereby scission occurs at different temperatures [48] [49]. Hence the broad temperature ranges $\left(200^{\circ} \mathrm{C}-700^{\circ} \mathrm{C}\right)$ for thermal degradation of these lignins. The TG curves of the lignin decomposition

Table 3. Effects of the processing method on molecular weight distribution in TC lignins.

\begin{tabular}{cccc}
\hline Sample & $\mathbf{M}_{\mathrm{w}}(\mathrm{g} / \mathrm{mol})$ & $\mathbf{M}_{\mathrm{n}}(\mathrm{g} / \mathrm{mol})$ & $\mathbf{M}_{\mathrm{w}} / \mathbf{M}_{\mathbf{n}}$ \\
\hline MWL & $10959 \pm 82$ & $3892 \pm 14$ & $2.8 \pm 0.0$ \\
ILL & $4157 \pm 19$ & $2238 \pm 15$ & $1.9 \pm 0.0$ \\
EOL & $2084 \pm 9$ & $1205 \pm 12$ & $1.7 \pm 0.0$ \\
\hline
\end{tabular}

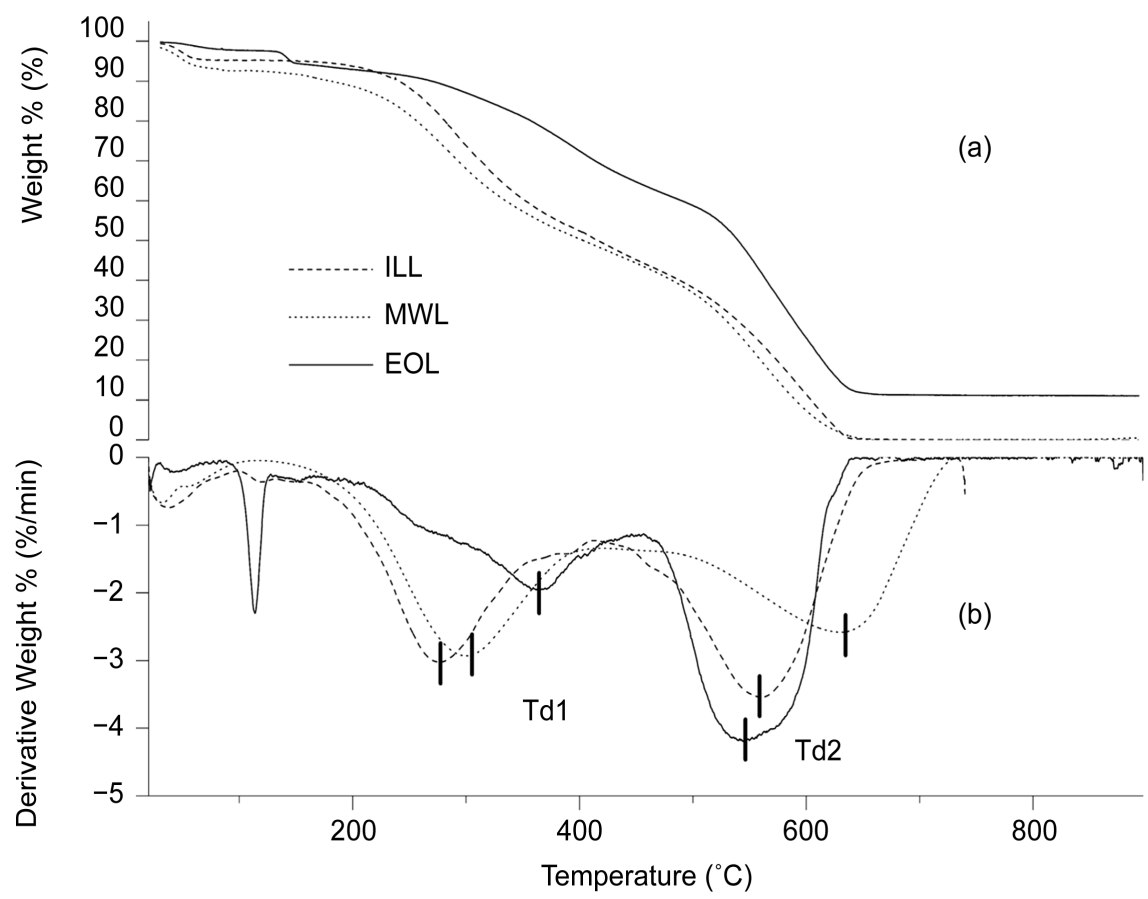

Figure 6. (a) Thermogravimetric curves (TG), (b) Thermal decomposition temperature curves (DTG). 
reveal a gentle sloping baseline and flat peaks that makes it difficult to determine an activation energy for the reaction. ILL exhibited very close thermal properties to the MWL, revealed in the two decomposition stages $\left(\mathrm{Td} 1: 270^{\circ} \mathrm{C}-365^{\circ} \mathrm{C}\right.$ and $\mathrm{Td} 2: 545^{\circ} \mathrm{C}-630^{\circ} \mathrm{C}$ ), Table 4 . Further similarity between the MWL and ILL is revealed, as both decomposed completely with zero residues whereas $11 \%$ residue remained in EOL from $700^{\circ} \mathrm{C}$ to the final temperature of $900^{\circ} \mathrm{C}$.

\section{Discussion}

IL treatment results in some chemical breakdown of the extracted lignin. In the present study, the chemical modification of lignin during IL extraction was studied and we compared with EOL and MWL.

Compared to MWL, the ILL had a higher extraction yield and purity, but lower molecular weight. The EOL exhibited less impurities, with hemicelluloses sugars and nitrogen as the major contributors to ILL impurities. The origin of nitrogen impurity in ILL was likely from the imidazole component of the 1-ethyl-3-methylimidazolium acetate. A purification effort was performed and although significant reduction in nitrogen impurities was achieved, it was not completely removed from the ILL. Elemental analysis data showed a value of $0.34 \%$ nitrogen in the cellulose rich fraction of ILL extraction, compared to $0.71 \%$ in $\mathrm{TC}_{\text {extracted }}$ and $2.78 \%$ in the ILL fraction after the purification step, indicating preferential attachment of imidazole to the lignin. Strong affinity of the imidazole to lignin could be attributed to attractive forces between the cation component of the ionic liquid and the $\mathrm{OH}$ groups of the lignin, leading to strong bonding. A similar contaminant that originated from 1-butylimidazolium hydrogen sulfate, which was used for lignin extraction was observed, and despite purification steps, it was never completely removed from the lignin [50].

In this study, the spectroscopic and chromatographic data obtained from the analysis of lignins demonstrated the following features:

- phenolic OH content : EOL $>>$ ILL $\approx$ MWL

- molecular masses: $\mathrm{EOL}<\mathrm{ILL}<\mathrm{MWL}$

A lower proportion of $\beta$-O-4 structures in EOL was observed by ${ }^{13} \mathrm{C}$ NMR. Scission of $\beta$-O-4 linkages and deconstruction of $\beta-\beta$ and $\beta-5$ ' linkages at higher temperatures may have led to the lower molecular weight in EOL. In addition, the higher carboxyl content detected in EOL in wet chemistry, quantitative NMR and FTIR methods, is in accordance with the formation of Hibbert's ketones, due to the acid-catalyzed solvolytic cleavage of aryl-ether linkages. Reduction in

Table 4. Thermal decomposition profiles of the 3 lignin isolates.

\begin{tabular}{cccccc}
\hline \multirow{2}{*}{ Sample } & $\mathrm{T} 5 \%$ & $\mathrm{~T} 10 \%$ & $\mathrm{Td} 1$ & $\mathrm{Td} 2$ & Ash \\
\cline { 2 - 6 } & $\mathrm{T}\left({ }^{\circ} \mathrm{C}\right)$ & $\mathrm{T}\left({ }^{\circ} \mathrm{C}\right)$ & $\mathrm{T}\left({ }^{\circ} \mathrm{C}\right)$ & $\mathrm{T}\left({ }^{\circ} \mathrm{C}\right)$ & $\mathrm{T}\left({ }^{\circ} \mathrm{C}\right)$ \\
\hline MWL & 130 & 218 & 298 & 630 & 715 \\
ILL & 141 & 235 & 270 & 553 & 650 \\
EOL & 120 & 235 & 365 & 545 & 701 \\
\hline
\end{tabular}


the aliphatic hydroxyl groups observed in EOL could be attributed to dehydration reactions on the lateral chain that occurred in view of the acidic conditions.

All these observations are rationalized by lower aryl-ether bond cleavage rate in ILL and MWL, due to milder conditions. According to George et al., when using imidazolium-based ionic liquid, the $\alpha$-aryl ether linkages cleavage is due to dehydration reaction, catalyzed by the EMIM anion basicity and its affinity towards water [13]. Furthermore, rather than acting as nucleophiles or a catalyst to cleave $\beta$-O-4 linkages, acetate anion in EMIM acts as weak nucleophile to remove $\mathrm{OH}$ groups from guaiacyl- $\beta$-guaiacyl ether-like linkages to form more stable vinyl ether linkages.

The ${ }^{13} \mathrm{C}$ NMR and thermo-physical analysis also revealed that the ILL is less condensed than EOL. This observation is based on the degree of condensation value of $0.42 / \mathrm{Ar}$ for ILL compared to $0.92 / \mathrm{Ar}$ in EOL, and the higher thermal stability of EOL. This is consistent with literature, as severe acidic conditions should lead to higher condensation [51]. Although EOL processing was catalyzed by mild dilute sulfuric acid - at high temperatures, cleavage of acetyl groups from hemicelluloses leads to the formation of acetic acid and carboxylic acids, thereby making the condition more acidic [52]. Similar observations of the high value of the degree of condensation was made by Granata and Argyropoulos in steam exploded lignins and was attributed to the scission of $\beta-\mathrm{O}-4$ bonds, leading to the release of the syringyl monomer [26]. This is in consonant with the fact that guaiacyl is more involved in the recondensation reaction, therefore while $\mathrm{G}$ decreases, $\mathrm{S}$ is increased. This also correlates with the highest value of the syringyl unit exhibited by EOL as reflected in ${ }^{31} \mathrm{P}$ NMR data. At the temperature range of $440^{\circ} \mathrm{C}-630^{\circ} \mathrm{C}$, where DTGmax occurred for the lignin samples, thermal degradation in this zone involved fragmentation of inter-unit linkages, releasing monomeric phenols into the vapor phase and decomposition of some aromatic rings [53]. Beyond this temperature range, the ILL and MWL revealed differing behavior, compared to EOL, by exhibiting complete decomposition, while EOL had about $11 \%$ of material remaining un-volatilized, indicating the formation of highly condensed aromatic structures [53] in EOL. Conversely, there were very low C-C linkages at this zone for ILL and MWL, resulting in more thermal degradation, where volatilized monomeric fragments were released into vapor phase, leading to complete decomposition. Moreover, inorganic salts and acids are known to act as flame retardants in pyrolysis and combustion, leading to an increase in ash yields [54] [55]. The presence of sulfates from any of the metallic substances earlier observed in EOL may have influenced the ash yield exhibited.

With a relatively lower degree of condensation, lower aromatic C-C structures and higher aliphatic $\mathrm{OH}$ than EOL, the ILL displays a chemical structure closer to that of MWL. Consequently, ILL could be useful in areas requiring high quality lignin with high ether contents and low C-C structures. Consequently, ILL could be useful in areas requiring high quality lignin with high ether contents and low C-C structures, for instant, for further depolymerization by chemical, 
enzymatic or thermal methods for the production of aromatic monomers.

\section{Conclusion}

The cleavage of ether linkages is primarily responsible for lignin breakdown in both ionic liquid and organosolv methods. The solvent's properties and treatment conditions influenced the depolymerization and functionalization of the lignin isolates from TC. The ILL from TC demonstrated higher aliphatic $\mathrm{OH}$ but low condensation because of low dehydration reactions and low $\mathrm{C}-\mathrm{C}$ bonds but higher $\beta$-O-4 structures compared to EOL. By and large, ILL exhibited closer structures and reactivity to the MWL counterpart than EOL. At the moderate condition of $110^{\circ} \mathrm{C}$, with no acid catalysis for ILL treatment, compared to the more severe condition of $170^{\circ} \mathrm{C}$, under dilute acid catalysis in EOL, lignin extraction using EMIMOAc IL looks promising as a greener technology, especially in view of the low energy requirement in its isolation and the possibility of recovery and reuse of the IL. In addition, there are possibilities to use ILL in applications requiring high quality lignin with high ether contents and low $\mathrm{C}-\mathrm{C}$ structures. In addition, there are possibilities to use ILL in applications requiring high quality lignin with high ether contents and low C-C structures, for example, aromatic monomers could be produced from ILL by further depolymerization using chemical, enzymatic or thermal methods. Findings revealed in the current study may provide valuable insights on the impact of ionic liquid mediated extraction on lignin depolymerization and may instigate further investigations in this direction towards identifying better techniques for utilizing lignocellulosic biomass.

\section{Acknowledgements}

This work was funded by Alexander von Humboldt Stiftung through its Georg Forster Postdoctoral Research Fellowship grant, the authors are grateful. The authors acknowledge and deeply appreciate the following: Frau Stibal E., Ms. Menana Z., and Herr Rudolf, A., who were very supportive in the logistics for prompt provision of chemicals for the various analysis conducted in Freiburg, Nancy and Tharandt respectively; Ms. Hagios, M. and Dr. Pacheco Torres, V. H. who performed the GPC and NMR experiments respectively; and Ms. Chan K. for proof reading the article.

\section{References}

[1] Aziz, S. and Sarkanen K. (1989) Organosolv Pulping-A Review. Tappi Journal, 72, $162-175$

[2] Delmas, M. (2008) Vegetal Refining and Agrochemistry. Chemical Engineering \& Technology, 31, 792-797. https://doi.org/10.1002/ceat.200800052

[3] Brosse, N., Ibrahim, M.N. and Abdul A. (2011) Biomass to Ethanol: Initiatives of the Future for Lignin. ISRN Materials Science, 2011, Article ID: 461482. https://doi.org/10.5402/2011/461482

[4] Audu, I.G., Brosse, N., Desharnais, L. and Rakshit, S.K. (2012) Ethanol Organosolv 
Pretreatment of Typha capensis for Bioethanol Production and Coproducts. BioResources, 7, 5917-5933. https://doi.org/10.15376/biores.7.4.5917-5933

[5] Sun, N., Rahman, M., Qin, Y., Maxim, M.L., Rodriguez, H. and Rogers, R.D. (2009) Complete Dissolution and Partial Delignification of Wood in Ionic Liquid 1-Ethyl3-Methylimidazolium Acetate. Green Chemistry, 11, 646-655. https://doi.org/10.1039/b822702k

[6] Lee, S.H., Doherty, T.V., Linhardt, R.J. and Dordick, J.S. (2009) Ionic Liquid-Mediated Selective Extraction of Lignin from Wood Leading to Enhanced Enzymatic Cellulose Hydrolysis. Biotechnology and Bioengineering, 102, 1368-1376. https://doi.org/10.1002/bit.22179

[7] Kadokawa, J.-I. (2013) Ionic Liquid as Useful Media for Dissolution, Derivatization, and Nanomaterial Processing of Chitin. Green and Sustainable Chemistry, 3, 19-25. https://doi.org/10.4236/gsc.2013.32A003

[8] Achinivu, E.C., Howar, R.M., Li, G., Gracz, H. and Henderson, W.A. (2014) Lignin Extraction from Biomass with Protic Ionic Liquids. Green Chemistry, 16, 1114 1119. https://doi.org/10.1039/C3GC42306A

[9] Zhao, H., Jones, C.L., Baker, G.A. and Xia, S. (2009) Regenerating Cellulose from Ionic Liquids for an Accelerated Enzymatic Hydrolysis. Journal of Biotechnology, 139, 47-54.

[10] Abushammala, H., Krossing, I. and Laborie, M.P. (2015) Ionic Liquid-Mediated Technology to Produce Cellulose Nanocrystals Directly from Wood. Carbohydrate Polymers, 134, 609-616.

[11] Abushammala, H., Goldsztayn, R., Leao, A. and Laborie, M.P. (2016) Combining Steam Explosion with 1-Ethyl-3-Methylimidazlium Acetate Treatment of Wood Yields Lignin-Coated Cellulose Nanocrystals of High Aspect Ratio. Cellulose, 23, 1813-1823. https://doi.org/10.1007/s10570-016-0911-4

[12] Kim, J.Y., Shin, E.J., Eom, I.-Y., Won, K., Kim, Y.H., Choi, D., Choi, I.-G. and Choi, J.W. (2011) Structural Features of Lignin Macromolecules Extracted with Ionic Liquid from Poplar Wood. Bioresource Technology, 102, 9020-9025.

[13] George, A., Tran, K., Morgan, T.J., Benke, P.I., Berrueco, C., Lorente, E., Wu, B.C., Keasling, J.D., Simmons, B.A. and Holmes, B.M. (2011) The Effect of Ionic Liquid Cation and Anion Combinations on the Macromolecular Structure of Lignins. Green Chemistry, 13, 3375-3385. https://doi.org/10.1039/c1gc15543a

[14] Cetinko, O.P., Dibble, D.C., Cheng, G., Kent, M.S., Knierim, B., Auer, M., Wemmer, D.E., Pelton, J.G., Melnichenko, Y.B., Ralph, J., Simmons, B.A. and Holmes, B.M. (2010) Understanding the Impact of Ionic Liquid Pretreatment on Eucalyptus. Biofuels, 1, 33-46. https://doi.org/10.4155/bfs.09.5

[15] Abushammala, H., Pontes, J.F., Gomes, G.H., Osorio-Madrazo, A., Thire, R.M.S.M., Pereiral, V.F. and Laborie, M.P. (2015) Swelling, Viscoelastic, and Anatomical Studies on Ionic Liquid-Swollen Norway Spruce as a Screening Tool toward Ionosolv Pulping. Holzforschung, 69, 1059-1067. https://doi.org/10.1515/hf-2014-0292

[16] Tan, H.T. and Lee, K.T. (2012) Understanding the Impact of Ionic Liquid Pretreatment on Biomass and Enzymatic Hydrolysis. Chemical Engineering Journal, 183, 448-458.

[17] Binder, J.B. and Raines, R.T. (2010) Fermentable Sugars by Chemical Hydrolysis of Biomass. Proceedings of the National Academy of Sciences of the United States of America, 107, 4516-4521. https://doi.org/10.1073/pnas.0912073107

[18] Kilpelainaen, I., Xie, H., King, A., Granstrom, M., Heikkinen, S. and Argyropoulos, D.S. (2007) Dissolution of Wood in Ionic Liquids. Journal of Agricultural and Food 
Chemistry, 55, 9142-9148. https://doi.org/10.1021/jf071692e

[19] Hames, B., Ruiz, R., Scarlata, C., Sluiter, A., Sluiter, J. and Templeton, D. (2008) Preparation of Samples for Compositional Analysis. In: Laboratory Analytical Procedure ( $L A P)$, National Renewable Energy Laboratory, Golden Co.

[20] Sluiter, A., Ruiz, R., Scarlata, C., Sluiter, J. and Templeton, D. (2008) Determination of Extractives in Biomass. In: Laboratory Analytical Procedure (LAP), NREL, Midwest Research Institute, Battelle.

[21] Obst, J.R. and Kirk, T.K. (1988) Isolation of Lignin. Methods in Enzymology, 161, 87-101.

[22] Rencoret, J., Marques, G., Gutierrez, A., Ibarra, D., Li, J., Gellerstedt, G., Santos, J.I., Jimene-Barbero, J., Martinez, A.T. and del Rio, J.C. (2008) Structural Characterization of Milled Wood Lignins from Different Eucalypt Species. Holzforschung, 62, 514-526. https://doi.org/10.1515/hf.2008.096

[23] Schafer, J., Urbat, F., Rund, K. and Bunzel, M.J. (2015) A Stable-Isotope Dilution GC-MS Approach for the Analysis of DFRC (Derivatization Followed by Reductive Cleavage) Monomers from Low Lignin Plant Materials. Journal of Agricultural and Food Chemistry, 63, 2668-2673. https://doi.org/10.1021/jf506221p

[24] Faix, O. (1992) Fourier Transform Infrared Spectroscopy. In: Lin, S.Y. and Dence, C.W., Eds., Methods in Lignin Chemistry, Springer-Verlag, Berlin, Heidelberg, 83109.

[25] Sarkanen, K.V., Chang, H.M. and Allan, G.G. (1967) Species in Lignins. I. Infra Red Spectra of Guaiacyl and Syringyl Models. Tappi Journal, 50, 572-575.

[26] Granata, A. and Argyropoulos, D.S. (1995) 2-Chloro-4,4,5,5-Tetramethyl-1,3,2-Dioxaphospholane, a Reagent for the Accurate Determination of the Uncondensed and Condensed Phenolic Moieties in Lignins. Journal of Agricultural and Food Chemistry, 43, 1538-1544. https://doi.org/10.1021/jf00054a023

[27] Asikkala, J., Tamminen, T. and Argyropoulos, D.S. (2012) Accurate and Reproducible Determination of Lignin Molar Mass by Acetobromination. Journal of Agricultural and Food Chemistry, 60, 8968-8973. https://doi.org/10.1021/jf303003d

[28] Vieböck, F. and Schwappach, A.A. (1930) Eine neue Methode zur maßanalytischen Bestimmung der Methoxyl-und Äthoxylgruppe. Berichte der Deutschen Chemischen Gesellschaft ( $A$ and B Series), 63, 2818-2823. https://doi.org/10.1002/cber.19300631022

[29] Zakis, G.F. (1997) Carbonyl Groups. In: Joyce T. and Brezny, R., Eds., The Functional Analysis of Lignins and Their Derivatives, Tappi Pr, Atlanta, 1-102.

[30] Chen, C.L. (1992) Determination of Carbonyl Groups. In: Lin, S.Y. and Dence, C.W., Eds., Methods in Lignin Chemistry, Springer, Berlin, Heidelberg, 409-422.

[31] Dence, C.W. (1992) Determination of Total and Aliphatic Hydroxyl Groups. In: Lin S.Y. and Dence, C.W., Eds., Methods in Lignin Chemistry, Springer, Berlin, Heidelberg, 409-422.

[32] Faix, O., Andersons, B. and Zakis, G. (1998) Determination of Carbonyl Groups of Six Round Robin Lignins by Modified Oximation and FTIR Spectroscopy. Holzforschung, 52, 268-274. https://doi.org/10.1515/hfsg.1998.52.3.268

[33] Mcdonough, T.J. (1992) The Chemistry of Organosolv Delignification. IPST Technical Paper Series No. 455.

[34] Guerra, A., Filpponen, I., Lucia, L.A. and Argyropoulos, D.S. (2006) Comparative Evaluation of Three Lignin Isolation Protocols for Various Wood Species. Journal of Agricultural and Food Chemistry, 54, 9696-9705.

https://doi.org/10.1021/jf062433c 
[35] Faix, O. (1991) Classification of Lignins from Different Botanical Origins by FT-IR Spectroscopy. Holzforschung, 45, 21-27. https://doi.org/10.1515/hfsg.1991.45.s1.21

[36] Lynch, B.M. and Durie, R.A. (1960) Comparative Studies of Brown Coal and Lignin: The Action of Concentrated Alkali at Elevated Temperatures. Australian Journal of Chemistry, 13, 567-581. https://doi.org/10.1071/CH9600567

[37] del Rio, J.C., Prinsen, P., Rencoret, J., Nieto, L., Jimenex-Barbero, J., Ralph, J., Martinez, A.T. and Gutierrez, A. (2012) Structural Characterization of the Lignin in the Cortex and Pith of Elephant Grass (Pennisetum purpureum) Stems. Journal of Agricultural and Food Chemistry, 60, 3619-3634. https://doi.org/10.1021/jf300099g

[38] Lu, F. and Ralph, J. (2002) Preliminary Evidence for Sinapyl Acetate as a Lignin Monomer in Kenaf. Chemical Communications, 1, 90-91. https://doi.org/10.1039/b109876d

[39] El Hage, R., Brosse, N., Sannigrahi, P. and Ragauskas, A. (2010) Effects of Process Severity on the Chemical Structure of Miscanthus Ethanol Organosolv Lignin. Polymer Degradation and Stability, 95, 997-1003.

[40] Boeriu, C.G., Bravo, D., Gosselink, R.J.A. and van Dam, R.E.G. (2004) Characterization of Structure-Dependent Functional Properties of Lignin with Infrared Spectroscopy. Industrial Crops and Products, 20, 205-218.

[41] Sammons, R.J., Harper, D.P., Labbe, N., Bozell, J.J., Elder, T. and Rials, T.G. (2013) Characterization of Organosolv Lignins Using Thermal and FT-IR Spectroscopic Analysis. BioResources, 8, 2752-2767. https://doi.org/10.15376/biores.8.2.2752-2767

[42] Capanema, E.A., Balakshin, M.Y. and Kadla. J.F. (2004) A Comprehensive Approach for Quantitative Lignin Characterization by NMR Spectroscopy. Journal of Agricultural and Food Chemistry, 52, 1850-1860. https://doi.org/10.1021/jf035282b

[43] Holtman, K.M., Chang, H.M. and Kadla, J.F. (2004) Solution-State Nuclear Magnetic Resonance Study of the Similarities between Milled Wood Lignin and Cellulolytic Enzyme Lignin. Journal of Agricultural and Food Chemistry, 52, 720-726. https://doi.org/10.1021/jf035084k

[44] Meng, L., Kang, S., Zhang, X., Wu, Y. and Sun, R. (2012) Comparative Characterization of Lignins Extracted from Cotton Stalk Based on Complete Dissolution in Different Systems. Industrial \& Engineering Chemistry Research, 51, 9858-9866. https://doi.org/10.1021/ie301118e

[45] Brunow, G. and Lindquist, K. (2010) Functional Groups and Bonding Patterns in Lignin (Including the Lignin-Carbohydrate Complexes). In: Heitner, C., Dimmel, D. and Schmidt, J.A., Eds., Lignin and Lignans. Advances in Chemistry, CRC Press, Boca Raton, 267-299. https://doi.org/10.1201/ebk1574444865-c7

[46] Geiger, H. and Fuggerer, H. (1979) Uber den Chemismus der Wiesener-reaktion auf lignin. Zeitschrift für Naturforschung, 34b, 1471-1472.

[47] Adler, E. and Marton, J.I. (1959) Zur kenntnis der Carbonylgruppen im Lignin. Acta Chemica Scandinavica, 13, 75-96. https://doi.org/10.3891/acta.chem.scand.13-0075

[48] Wang, S., Wang, K., Liu, Q., Gu, Y., Luo, Z., Cen, K. and Fransson, T. (2009) Comparison of the Pyrolysis Behavior of Lignins from Different Tree Species. Biotechnology Advances, 27, 562-567.

[49] Scholze, B. and Meier, D. (2001) Characterization of Water Soluble Fraction from Pyrolysis Oil (Pyrolysis Lignin). Journal of Analytical and Applied Pyrolysis, 60, 4154.

[50] Brandt, A., Chen, L., van Dongen, B.E., Welton, T. and Hallett, J.P. (2015) Structural Changes in Lignins Isolated Using an Acidic Ionic Liquid Water Mixture. Green 
Chemistry, 17, 5019-5034. https://doi.org/10.1039/C5GC01314C

[51] Faix, O., Stevanovic-Janezic, T. and Lundquist, K. (1994) The Lignin of the Diffuse Porous Angiosperm Tree Triplochyton scleroxylon K. Schum with Low Syringyl Content. Journal of Wood Chemistry and Technology, 14, 263-278. https://doi.org/10.1080/02773819408003097

[52] Romero, I., Moya, M., Sanchez, S., Ruiz, E., Castro, E. and Bravo, V. (2007) Ethanolic Fermentation of Phosphoric Acid Hydrolysates from Olive Tree Pruning. Industrial Crops and Products, 25, 160-168.

[53] Tejado, A., Peña, C., Labidi, J., Echeverria, J.M. and Mondragon, I. (2007) Physico-Chemical Characterization of Lignins from Different Sources for Use in Phenol-Formaldehyde Resin Synthesis. Bioresource Technology, 98, 1655-1663.

[54] Roman, M. and Winter, W.T. (2004) Effect of Sulfate Groups from Sulfuric Acid Hydrolysis on the Thermal Degradation Behavior of Bacterial Cellulose. Biomacromolecules, 5, 1671-1677. https://doi.org/10.1021/bm034519+

[55] Tang, W.K. and Neill, W.K. (1964) Effect of Flame Retardants on Pyrolysis and Decomposition of Cellulose. Journal of Polymer Science Part C, 6, 65-81. 


\section{Supplementary Materials}

\section{Procedure for MWL Isolation}

The procedure by Bjorkman as modified by Obst and Kirk [1] and Rencoret et al. [2], was used to process MWL from TC. The EFTC was ball milled in batches of about $40 \mathrm{~g}$ in $500 \mathrm{~mL}$ grinding jars with $20 \mathrm{~mL}$ steel balls using a Retsch Planetary Ball Mill PM 100 for $50 \mathrm{~h}$. The mill was programmed to operate at intervals of 10 minutes active milling followed by 5 minutes rest and reverse rotation after each 5 minutes milling to avoid overheating and agglomeration. A total of $100 \mathrm{~g}$ of ball milled TC was placed in $2 \mathrm{~L}$ round bottom flask and $1 \mathrm{~L}$ of $96 \%$ aqueous dioxane was added and magnetic stirred at room temperature for $24 \mathrm{~h}$. The mixture was centrifuged to separate insoluble material while the lignin contained in the supernatant was recovered by evaporating the liquids to dryness under reduced pressure at $40^{\circ} \mathrm{C}$ using rotary evaporator - Buchi rotavapo R-210 (equipped with vacuum controller V-850 and heating bath B-491). The process was repeated 2 times and lignin joined together. The dry lignin residue was dissolved by pouring $30 \mathrm{~mL}$ of acetic acid/water (9:1, v/v) into the round bottom flask containing the lignin. Lignin was precipitated by adding the acetic acid water lignin mixture dropwise to $300 \mathrm{~mL}$ of stirred water and separated by centrifuging for 30 minutes at $4700 \mathrm{rpm}$. The precipitated lignin was re-dissolved in 30 $\mathrm{ml}$ solution of dichloromethane: ethanol $(2: 1, \mathrm{v} / \mathrm{v})$ and the mixture was then centrifuged to remove insoluble material. Lignin was precipitated using $300 \mathrm{~mL}$ of diethyl ether separated by centrifuge.

\section{Procedure for Determination of Functional Groups Using Wet Chemistry Methods}

Detail procedure for determination of each functional groups are described as follows:

\section{Determination of methoxy contents}

The procedure by Vieböck and Schwappach [3] detailed by Zakis [4] was used to determine the methoxy contents. The mechanism of action of the procedure is based on the following series of reactions:

$$
\begin{aligned}
& \mathrm{R}-\mathrm{OCH}_{3}+\mathrm{HI} \rightarrow \mathrm{R}-\mathrm{OH}+\mathrm{CH}_{3} \mathrm{I} \\
& \mathrm{CH}_{3} \mathrm{I}+\mathrm{Br}_{2} \rightarrow \mathrm{CH}_{3} \mathrm{Br}+\mathrm{IBr} \\
& \mathrm{IBr}+2 \mathrm{Br}_{2}+3 \mathrm{H}_{2} \mathrm{O} \rightarrow \mathrm{HIO}_{3}+5 \mathrm{HBr} \\
& \mathrm{HIO}_{3}+5 \mathrm{HI} \rightarrow 3 \mathrm{I}_{2}+3 \mathrm{H}_{2} \mathrm{O} \\
& 3 \mathrm{I}_{2}+6 \mathrm{Na}_{2} \mathrm{~S}_{2} \mathrm{O}_{2} \rightarrow 6 \mathrm{NaI}+3 \mathrm{Na}_{2} \mathrm{~S}_{4} \mathrm{O}_{6}
\end{aligned}
$$

First $20-25 \mathrm{mg}$ of dried sample was weighed in the reaction chamber, then $0.2 \mathrm{~g}$ red phosphorus, $0.5 \mathrm{~g}$ phenol, 6 drops of acetic anhydride and $5 \mathrm{~mL}$ hydroiodic acid were added. The Vieböck Schwappach apparatus was then coupled allowing carbon dioxide gas to flow through the gas inlet into the reaction chamber at about 1 bubble per 2 seconds flow rate. The mixture was boiled for 1 
hour by heating to $140^{\circ} \mathrm{C}$ in an oil bath. At the end of $1 \mathrm{hr}$ boiling, the apparatus was decoupled and content of the reaction chamber quantitatively transferred into an Erlenmeyer flask containing $1.5 \mathrm{~g}$ sodium acetate dissolved in a little water. The reaction chamber was rinsed into the Erlenmeyer flask several times with total of about $150 \mathrm{~mL}$ deionized water. Then formic acid was added dropwise until the solution became fully discolored. The content was kept for about 5 minutes and 3 drops of methyl red added followed by $10 \mathrm{~mL}$ of solution of potassium iodide (10 g in $100 \mathrm{~mL}$ deionized water) and $5 \mathrm{~mL}$ dilute $\mathrm{H}_{2} \mathrm{SO}_{4}$ acid $(50 \% \mathrm{v} / \mathrm{v})$ added. The solution was then titrated using sodium thiosulphate standard solution with $1 \%$ starch solution as an indicator.

Methoxy content was calculated by the relationship:

$$
\mathrm{OCH}_{3}\left[\mathrm{mmol} \cdot \mathrm{g}^{-1}\right]=\frac{c^{*}(v / 6) * \tau}{m}
$$

where $c$ is the concentration of $\mathrm{Na}_{2} \mathrm{~S}_{2} \mathrm{O}_{3}\left[\mathrm{~mol} \cdot \mathrm{L}^{-1}\right], V$ is the volume of $\mathrm{Na}_{2} \mathrm{~S}_{2} \mathrm{O}_{3}$ required [mL], 6 is the ratio of $\mathrm{n}\left(\mathrm{OCH}_{3}\right) / \mathrm{n}\left(\mathrm{Na}_{2} \mathrm{~S}_{2} \mathrm{O}_{3}\right), \tau$ is the factor of $\mathrm{Na}_{2} \mathrm{~S}_{2} \mathrm{O}_{3}$, and $\mathrm{m}$ is the sample's weight $[\mathrm{g}]$.

\section{Determination of total hydroxyl contents}

Hydroxyl content consisting of phenolic and aliphatic hydroxyl was determined using acetylated lignin samples based on procedure by Chen [5]. The technic is based on acetylation and cleavage of the acetate to produce acetic acid, obtained acetic acid is then titrated using $\mathrm{NaOH}$.

$60 \mathrm{mg}$ of samples were weighed in a $50 \mathrm{~mL}$ double necked flask, $4 \mathrm{~mL} \mathrm{H} \mathrm{H}_{2} \mathrm{~S}_{4}$ acid $(50 \%, v / v)$ added and magnetic stirring rod inserted. The flask was coupled to reflux condenser and second neck closed with stopper, all joints sealed with grease that have been tested to be blank. The mixture was heated with stirring to its boiling point in an oil bath at $120^{\circ} \mathrm{C}$ for 1 hour. The mixture was then relieved from the oil bath and $10 \mathrm{~mL}$ deionized water added from the top of the reflux condenser. The mixture was then boiled again for 10 minutes, relieved from the oil bath and left to cool down for 10 minutes. The reflux condenser was rinsed with deionized water into the flask and the flask was decoupled from the reflux condenser and coupled to a short path distillation apparatus with a thermometer and a $100 \mathrm{~mL}$ round-bottom flask as receiver flask. The second neck was rinsed and replaced with dropping funnel without pressure compensator. The mixture was heated to begin distillation and deionized water gradually added using the dropping funnel each time the temperature drops below $100^{\circ} \mathrm{C}$. When about $70 \mathrm{~mL}$ distillate is obtained, the distillation is stopped and distillate quantitatively transferred into an Erlenmeyer flask and 3 - 5 drops of phenolphthalein added followed by titration with $0.1 \mathrm{~N} \mathrm{NaOH}$. Blank is performed with unacetylated lignin. Total hydroxyl content was calculated using the formula below.

$$
[\mathrm{OH}] \%=\frac{\tau * V * 170}{m-4.2 * \tau * V}
$$


where $\tau$ is the concentration factor of the standard solutions, $V$ is the titer value obtained by the difference between the sample and blank titer values, 170 is a factor $\left(\mathrm{c}[\mathrm{NaOH}][\mathrm{mol} / \mathrm{L}]{ }^{\star} \mathrm{M}(\mathrm{OH})[\mathrm{g} / \mathrm{mol}] * 100[\%], \mathrm{m}\right.$ is weight of sample and 4.2 is the factor from $\left(\mathrm{c}[\mathrm{NaOH}][\mathrm{mol} / \mathrm{L}] *\left(\mathrm{M}\left\{\mathrm{OC}-\mathrm{CH}_{3}\right\}[\mathrm{g} / \mathrm{mol}]-\mathrm{M}(\mathrm{H})[\mathrm{g} / \mathrm{mol}]\right)\right.$

Determination of carboxyl and phenolic contents

Carboxyl groups are determined based on acidity of this group by a neutralization process of the carboxylic acid using a potentiometry to detect the titrimetric end point [6]. Concurrently, the weakly acidic phenolic hydroxyl groups can be determined. The procedure entails non-aqueous potentiometric titration of lignin with tetra- $n$-butylammoniumhydroxide in the presence of $\mathrm{p}$-hydroxybenzoic acid as internal standard. The procedure outlined by Dence [6] with slight modification was used to determine the phenolic and carboxylic groups. A specialized equipment for this is the automated Titroline Alpha by Schott with $\mathrm{Pt}$ 6280 electrode consisting of an input keyboard, a pumping device connected to the standard solution tank for titration, a magnetic stirrer and a PC for data acquisition. Titer values for lignin samples, blank and internal standard have been optimized, so specified range of titer values for stopping the titration have been documented during which the required inflexion points for calculations may have been acquired. First, standard solution was prepared by weighing $62.5 \mathrm{~g}$ tetra-n-butylammonium hydroxide $(\mathrm{TnBAH})$ into a $3 \mathrm{~L}$ chemical bottle and $2 \mathrm{~L}$ isopropyl alcohol was added and mixed thoroughly to obtain $0.05 \mathrm{M}$ of TnBAH standard solution.

To obtain the concentration of TnBAH, $0.15 \mathrm{~g}$ benzoic acid was weighed into a titration vessel and $30 \mathrm{~mL}$ DMF added and stirred for 30 minutes. This was followed by titration using the standard solution to stop at about $30 \mathrm{~mL}$ titer value from which $\mathrm{TnBAH}$ concentration was determined using equation:

$$
N\left(\frac{\mathrm{mol}}{\mathrm{L}}\right)=\frac{M(\text { benzoicacid })[\mathrm{g}]}{V(\mathrm{TnBAH})[\mathrm{mL}] 0.12212}
$$

where 0.12212 benzoic acid factor (molar mass of benzoic acid [g/mol]/1000).

At least two replications of each sample was analyzed by weighing $0.35 \mathrm{~g}$ of the sample and $0.07 \mathrm{~g}$ p-hydroxybenzoic acid in Erlenmeyer flask, then $30 \mathrm{~mL}$ DMF added and stirred for 30 minutes. This was followed by titration using the standard solution to about $65 \mathrm{~mL}$ titer value when the inflection points were recorded.

Theoretical consumption a, assigned to the internal standard (p-hydroxybenzoic acid) in $\mathrm{mL}$ is given by equation:

$$
a=\frac{m}{0.13812 N(\text { TnBAH })}
$$

where $m$ is the weight of p-hydroxybenzoic acid, 0.13812 is the molar mass of p-hydroxybenzoic acid $\left[\mathrm{g} \cdot \mathrm{mol}^{-1} / 1000\right], N(\mathrm{TnBAH})$ is the concentration of TnBAH solution as calculated in equation earlier.

Carboxyl content in $\mathrm{mmol} \cdot \mathrm{g}^{-1}$ is obtained by: 


$$
\mathrm{COOH}=\frac{\left(V_{x}-a\right)^{*} N(\mathrm{TnBAH})}{m}
$$

where $V_{x}$ is titer value up to the first inflection point $(\mathrm{mL}), a$ is the theoretical consumption as calculated, $N(\mathrm{TnBAH})$ is the concentration of TnBAH in $\mathrm{mol} / \mathrm{L}$, and $\mathrm{m}$ is lignin sample weight in $\mathrm{g}$.

The phenolic hydroxyl content in $\mathrm{mmol} \cdot \mathrm{g}^{-1}$ is calculated using the equation:

$$
\mathrm{OH}=\frac{\left(V_{y}-V_{x}-a\right) * N(\mathrm{TnBAH})}{m}
$$

where $V_{x}$ and $V_{y}$ are the titer values up to the first and second inflection points $(\mathrm{mL})$ respectively, $a$ is the theoretical consumption of p-hydroxybenzoic acid, $N(\mathrm{TnBAH})$ is the concentration of TnBAH in mol/L, $m$ is the lignin sample weight in $\mathrm{g}$.

\section{Determination of Carbonyl content}

The procedure based on oximation of carbonyl groups using hydroxylamine hydrochloride was applied in this process [4] [7]. Triethanolamine is added which reacts with the released hydrochloric acid to shift the equilibrium of the reaction to oxime formed and the excess base is titrated with standard solution of hydrochloric acid. Reactions involved are as below:

$$
\begin{gathered}
\mathrm{R}_{2} \mathrm{C}=\mathrm{O}+\mathrm{NH}_{2} \mathrm{OH} \cdot \mathrm{HCl} \leftrightarrow \mathrm{R}_{2} \mathrm{C}=\mathrm{NOH}+\mathrm{HCl}+\mathrm{H}_{2} \mathrm{O} \\
\mathrm{HCl}+\left(\mathrm{CH}_{2} \mathrm{CH}_{2} \mathrm{OH}\right)_{3} \mathrm{~N} \rightarrow\left(\mathrm{CH}_{2} \mathrm{CH}_{2} \mathrm{OH}\right)_{3} \mathrm{NH}^{+}+\mathrm{Cl}^{-}
\end{gathered}
$$

Two solutions were prepared. Solution one - $1.2 \mathrm{~g}$ of triethanolamine was weighed in $50 \mathrm{~mL}$ volumetric flask and volume made up to the mark using undenatured $96 \%(\mathrm{v} / \mathrm{v})$ ethanol and stirred. Solution two was prepared by weighing $0.7 \mathrm{~g}$ hydroxyammonium chloride into $50 \mathrm{~mL}$ volumetric flask and dissolved by adding $5 \mathrm{~mL}$ deionized water then $25 \mathrm{~mL}$ of solution one added and volume made up using un-denatured $96 \%(\mathrm{v} / \mathrm{v})$ ethanol.

Sample analysis was carried out by weighing $80 \mathrm{mg}$ of dry lignin in a test tube, then $2 \mathrm{~mL}$ DMSO was added and mixed thoroughly to dissolve. $5 \mathrm{~mL}$ of solution two was added and thoroughly mixed. The tube was placed in water bath at $80^{\circ} \mathrm{C}$ for 5 minutes then sealed with rubber stopper and heating continues for $2 \mathrm{~h}$. This was followed by quantitatively transferring the solution into a beaker and titrated using $0.05 \mathrm{~N} \mathrm{HCl}$ to $\mathrm{pH}$ 3.3. The procedure was repeated for blank without lignin sample.

Carbonyl content in $\mathrm{mmol} \cdot \mathrm{g}^{-1}$ was calculated using the relation:

$$
\mathrm{CO}\left[\mathrm{mmol} \cdot \mathrm{g}^{-1}\right]=\frac{c^{*} V^{*} \tau}{m}
$$

where $c$ is the concentration of $\mathrm{HCl}\left(\mathrm{mol} \cdot \mathrm{L}^{-1}\right), V$ is the volume of $\mathrm{HCl}$ obtained from the difference of titer values of samples and that of the blank, $\tau$ is the $\mathrm{HCl}$ concentration factor, and $m$ is weight of sample. 
Table S1. Elemental composition of $\mathrm{TC}_{\text {extracted }}$, lignin isolates and IL CR, values in \%.

\begin{tabular}{cccccc}
\hline Sample & $\mathrm{TC}_{\text {extracted }}$ & MWL & ILL & EOL & IL CR \\
\hline Carbon & $45.02 \pm 1.24$ & $57.32 \pm 0.84$ & $56.11 \pm 1.22$ & $56.31 \pm 0.91$ & $46.21 \pm 0.72$ \\
Hydrogen & $5.88 \pm 0.04$ & $5.89 \pm 0.08$ & $6.6 \pm 0.14$ & $5.61 \pm 0.23$ & $6.2 \pm 0.15$ \\
Nitrogen & $0.71 \pm 0.02$ & $0.39 \pm 0.00$ & $5.8 \pm 0.25,{ }^{\mathrm{a}} 2.78 \pm 0.12$ & $0.84 \pm 0.03$ & $0.3 \pm 0.05$ \\
Oxygen & $47.97 \pm 0.56$ & $36.4 \pm 0.38$ & $31.91 \pm 1.04$ & $35.23 \pm 0.34$ & $47.29 \pm 1.68$ \\
Sulfur & $0.42 \pm 0.24$ & $\mathrm{ND}$ & $\mathrm{ND}$ & $2.01 \pm 0.08$ & $\mathrm{ND}$ \\
\hline
\end{tabular}

$\mathrm{TC}_{\text {extracted }}$ - Extractive free TC; IL CR - cellulose rich fraction from ionic liquid procedure; ${ }^{\text {a }}$ value after purification steps.

Table S2. Absorbance and assignment of IR spectra of the 3 lignins (MWL, ILL \& EOL).

\begin{tabular}{|c|c|c|c|c|}
\hline \multirow{2}{*}{ Band range $\left(\mathrm{cm}^{-1}\right)$} & MWL & IIL & EOL & \multirow{2}{*}{ Assignment } \\
\hline & \multicolumn{3}{|c|}{ Intensity } & \\
\hline $3500-3300$ & 1.13 & 1.12 & 1.54 & $\begin{array}{l}\text { Presence of alcoholic and phenolic } \mathrm{OH} \text { groups } \\
\text { stretching vibrations }\end{array}$ \\
\hline \multirow{2}{*}{$3000-2842$} & 0.52 & 0.69 & 0.66 & $\mathrm{C}-\mathrm{H}$ stretching in methyl and methylene groups \\
\hline & 0.00 & 0.00 & 0.36 & Vibrations of $\mathrm{CH}_{2}$ anf $\mathrm{CH}_{3}$ groups \\
\hline $1740-1720$ & 0.71 & & & Alcoholic Acetate carbonyl \\
\hline $1719-1705$ & & & 0.80 & $\begin{array}{l}\mathrm{C}=\mathrm{O} \text { stretch in unconjugated ketnoes, carbonyl } \\
\text { and ester groups }\end{array}$ \\
\hline 1654 & & 1.04 & & $\mathrm{C}=\mathrm{O}$ stretch in unconjugated p-sybst. aryl ketones \\
\hline $1616-1600$ & 0.82 & 0.00 & 1.02 & $\mathrm{C}=\mathrm{C}$ stretching of aromatic ring in lignin \\
\hline 1567 & & 0.99 & & $\mathrm{C}=\mathrm{C}$ stretching (ionic compounds only) \\
\hline $1515-1505$ & 4.00 & 1.00 & 1.00 & $\mathrm{C}=\mathrm{C}$ stretching of aromatic ring in lignin \\
\hline $1470-1460$ & 0.87 & 0.87 & 0.89 & $\mathrm{C}-\mathrm{H}$ deformation; asym, in $-\mathrm{CH}_{3}$ and $-\mathrm{CH}_{2}-$ \\
\hline $1460-1422$ & 0.73 & 0.78 & & $\begin{array}{l}\text { Aromatic skeletal vibrations combined with C-H } \\
\text { in plane deformation }\end{array}$ \\
\hline $1386-1371$ & 0.62 & 0.65 & & $\mathrm{C}-\mathrm{H}$ deformation symmetric \\
\hline $1330-1323$ & 0.65 & 0.69 & & $\begin{array}{l}\mathrm{S} \text { ring plus } \mathrm{G} \text { ring condensed; i.e. } \mathrm{G} \text { ring } \\
\text { substituted in pos. } 5\end{array}$ \\
\hline $1270-1260$ & 1.19 & 0.76 & 1.05 & $\mathrm{G}$ ring plus $\mathrm{C}=\mathrm{O}$ stretch \\
\hline $1230-1217$ & 1.17 & 0.80 & 1.20 & $\mathrm{C}-\mathrm{C}, \mathrm{C}-\mathrm{O}$ AND $\mathrm{C}=\mathrm{O}$ stretching of $\mathrm{G}$ \\
\hline $1166-1163$ & & 0.66 & & C-N stretch in aliphatics \\
\hline $1128-1118$ & 1.17 & 0.98 & 1.79 & $\begin{array}{l}\text { aromatic } \mathrm{C}-\mathrm{H} \text { deformation of } \mathrm{S} \text {, plus secondary } \\
\text { alcohols }+\mathrm{C}=\mathrm{O} \text { stretch }\end{array}$ \\
\hline 1088 & & 0.80 & & $\begin{array}{l}\text { C-O deformation in secondary alcohols and } \\
\text { aliphatic ethers }\end{array}$ \\
\hline $1040-1030$ & 1.10 & 0.90 & 0.52 & $\mathrm{C}-\mathrm{O}$ stretching of primary alcohols \\
\hline $835-834$ & 0.23 & 0.17 & 0.16 & $\begin{array}{l}\mathrm{C}-\mathrm{H} \text { out of plane in positions } 2 \text {, and } 6 \text { of } \mathrm{S} \text {, } \\
\text { and in all positions of } \mathrm{H} \text { units }\end{array}$ \\
\hline
\end{tabular}



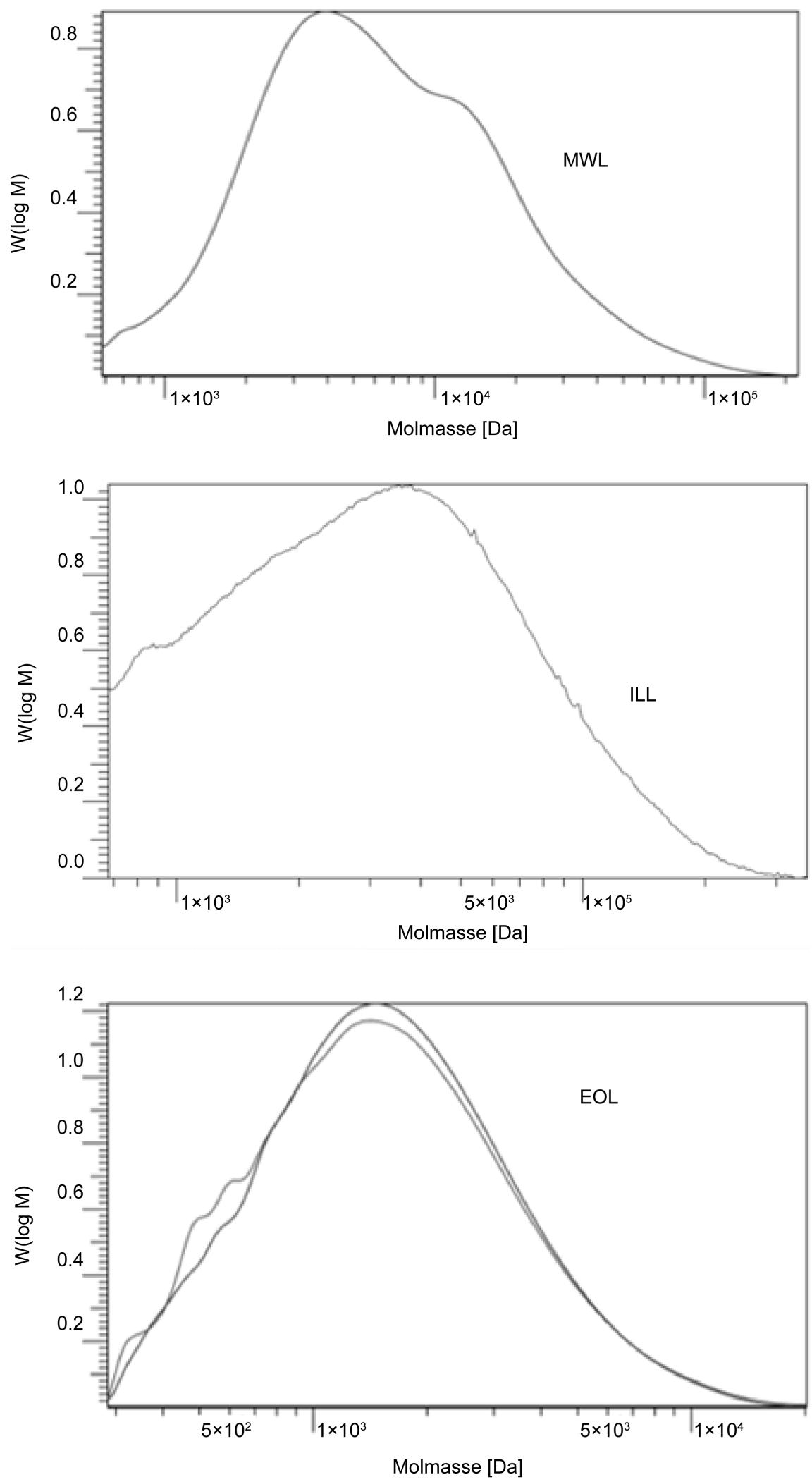

Figure S1. Gel permeation chromatography (GPC) curves of MWL, ILL and EOL.

\section{References}

[1] Obst, J.R. and Kirk, T.K. (1988) Isolation of Lignin. Methods in Enzymology, 161, 
87-101.

[2] Rencoret, J., Marques, G., Gutierrez, A., Ibarra, D., Li, J., Gellerstedt, G., Santos, J.I., Jimene-Barbero, J., Martinez, A.T. and del Rio, J.C. (2008) Structural Characterization of Milled Wood Lignins from Different Eucalypt Species. Holzforschung, 62, 514-526. https://doi.org/10.1515/hf.2008.096

[3] Vieböck, F. and Schwappach, A.A. (1930) Eine neue Methode zur maßanalytischen Bestimmung der Methoxyl und äthoxylgruppe. Berichte der Deutschen Chemischen Gesellschaft ( $A$ and B Series), 63, 2818-2823. https://doi.org/10.1002/cber.19300631022

[4] Zakis, G.F. (1997) Carbonyl Groups. In: Joyce, T. and Brezny, R., Eds., The Functional Analysis of Lignins and Their Derivatives, Tappi Pr, Atlanta, 1-102.

[5] Chen, C.L. (1992) Determination of Carbonyl Groups. In: Lin, S.Y. and Dence, C.W., Eds., Methods in Lignin Chemistry, Springer, Berlin, Heidelberg, 409-422.

[6] Dence, C.W. (1992) Determination of Total and Aliphatic Hydroxyl Groups. In: Lin S.Y. and Dence, C.W., Eds., Methods in Lignin Chemistry, Springer, Berlin, Heidelberg, 409-422.

[7] Faix, O., Andersons, B. and Zakis, G. (1998) Determination of Carbonyl Groups of Six Round Robin Lignins by Modified Oximation and FTIR Spectroscopy. Holzforschung, 52, 268-274. https://doi.org/10.1515/hfsg.1998.52.3.268

Submit or recommend next manuscript to SCIRP and we will provide best service for you:

Accepting pre-submission inquiries through Email, Facebook, LinkedIn, Twitter, etc. A wide selection of journals (inclusive of 9 subjects, more than 200 journals) Providing 24-hour high-quality service

User-friendly online submission system

Fair and swift peer-review system

Efficient typesetting and proofreading procedure

Display of the result of downloads and visits, as well as the number of cited articles Maximum dissemination of your research work

Submit your manuscript at: http://papersubmission.scirp.org/

Or contact gsc@scirp.org 